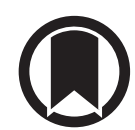

CrossMark

\title{
Imaging of pulmonary hypertension in adults: a position paper from the Fleischner Society
}

\begin{abstract}
Martine Remy-Jardin ${ }^{1,18}$, Christopher J. Ryerson ${ }^{2}$, Mark L. Schiebler ${ }^{3}$, Ann N.C. Leung ${ }^{4}$, James M. Wild ${ }^{5}$, Marius M. Hoeper ${ }^{6}$, Philip O. Alderson ${ }^{7}$, Lawrence R. Goodman ${ }^{8}$, John Mayo ${ }^{9}$, Linda B. Haramati ${ }^{10}$, Yoshiharu Ohno ${ }^{11}$, Patricia Thistlethwaite ${ }^{12}$, Edwin J.R. van Beek ${ }^{13}$, Shandra Lee Knight ${ }^{14}$, David A. Lynch ${ }^{15}$, Geoffrey D. Rubin ${ }^{16}$ and Marc Humbert ${ }^{17,19}$

Affiliations: ${ }^{1}$ Dept of Thoracic Imaging, Hôpital Calmette, Boulevard Jules Leclercq, Lille, France. ${ }^{2}$ Dept of Medicine, University of British Columbia and Centre for Heart Lung Innovation, St Paul's Hospital, Vancouver, BC, Canada. ${ }^{3}$ Dept of Radiology, UW-Madison School of Medicine and Public Health, Madison, WI, USA. ${ }^{4}$ Dept of Radiology, Stanford University Medical Center, Stanford, CA, USA. ${ }^{5}$ Division of Imaging, Dept of Infection Immunity and Cardiovascular Disease, University of Sheffield, Sheffield, UK. ${ }^{6}$ Dept of Respiratory Medicine, Hannover Medical School and German Centre of Lung Research (DZL), Hannover, Germany. ${ }^{7}$ Dept of Radiology, Saint Louis University School of Medicine, St Louis, MO, USA. ${ }^{8}$ Dept of Radiology, Medical College of Wisconsin, Milwaukee, WI, USA. ${ }^{9}$ Dept of Radiology, Vancouver General Hospital, Vancouver, BC, Canada. ${ }^{10}$ Dept of Radiology and Medicine, Montefiore Medical Center and Albert Einstein College of Medicine, Bronx, NY, USA. ${ }^{11}$ Dept of Radiology, Fujita Health University School of Medicine, Toyoake, Japan. ${ }^{12}$ Division of Cardiothoracic Surgery, University of California, San Diego, La Jolla, CA, USA. ${ }^{13}$ Edinburgh Imaging, Queens Medical Research Institute, University of Edinburgh, Edinburgh, UK. ${ }^{14}$ Dept of Library and Knowledge Services, National Jewish Health, Denver, CO, USA. ${ }^{15}$ Dept of Radiology, National Jewish Health, Denver, CO, USA. ${ }^{16}$ Dept of Radiology, Duke University School of Medicine, Durham, NC, USA. ${ }^{17}$ Université Paris Saclay, Inserm UMR S999, Dept of Pneumology, AP-HP, Pulmonary Hypertension Reference Center, Hôpital de Bicêtre, Le Kremlin Bicêtre, France. ${ }^{18}$ Chair of the Fleischner Society writing committee of the position paper for imaging of pulmonary hypertension. ${ }^{19} \mathrm{Co}$-Chair of the Fleischner Society writing committee of the position paper for imaging of pulmonary hypertension.
\end{abstract}

Correspondence: Martine Remy-Jardin. E-mail: martine.remylachru-lille.fr

@ERSpublications

From the Fleischner Society: This systematic review and position paper highlights the key role of imaging in the recognition, work-up, treatment planning, and follow-up of pulmonary hypertension in adults https://bit.ly/343kgbN

Cite this article as: Remy-Jardin M, Ryerson CJ, Schiebler ML, et al. Imaging of pulmonary hypertension in adults: a position paper from the Fleischner Society. Eur Respir J 2021; 57: 2004455 [https://doi.org/ 10.1183/13993003.04455-2020].

ABSTRACT Pulmonary hypertension $(\mathrm{PH})$ is defined by a mean pulmonary artery pressure greater than $20 \mathrm{mmHg}$ and classified into five different groups sharing similar pathophysiologic mechanisms, haemodynamic characteristics, and therapeutic management. Radiologists play a key role in the multidisciplinary assessment and management of $\mathrm{PH}$. A working group was formed from within the Fleischner Society based on expertise in the imaging and/or management of patients with $\mathrm{PH}$, as well as experience with methodologies of systematic reviews. The working group identified key questions focusing on the utility of CT, MRI, and nuclear medicine in the evaluation of $\mathrm{PH}: a$ ) Is noninvasive imaging capable of identifying $\mathrm{PH}$ ? b) What is the role of imaging in establishing the cause of $\mathrm{PH}$ ? c) How does imaging determine the severity and complications of $\mathrm{PH}$ ? d) How should imaging be used to assess chronic thromboembolic $\mathrm{PH}$ before treatment? e) Should imaging be performed after treatment of PH? This systematic review and position paper highlights the key role of imaging in the recognition, work-up, treatment planning, and follow-up of $\mathrm{PH}$.

This article has supplementary material available from erj.ersjournals.com

Received: 15 July 2020 | Accepted after revision: 28 Oct 2020

(C) 2021 European Respiratory Society and RSNA. This article is a simultaneous joint publication in the European Respiratory Journal and Radiology. The articles are identical except for stylistic changes in keeping with each journal's style. Either version may be used in citing this article. 


\section{Introduction}

Pulmonary hypertension $(\mathrm{PH})$ is a haemodynamic condition defined by a mean pulmonary artery pressure (PAP) greater than $20 \mathrm{mmHg}$ and classified into different groups sharing similar pathophysiologic mechanisms, haemodynamic characteristics, and therapeutic management [1-6] (table 1). The diagnostic process starts after the clinical suspicion of $\mathrm{PH}$ and echocardiography compatible with $\mathrm{PH}$ and continues with the identification of the more common clinical groups of $\mathrm{PH}$ (such as group 2 due to chronic left heart disease and group 3 due to chronic lung diseases), then distinguishes group 4 due to chronic thromboembolic $\mathrm{PH}(\mathrm{CTEPH})$, and finally makes the diagnosis of group 1 pulmonary arterial hypertension $(\mathrm{PAH})$, which is a diagnosis of exclusion.

This overview of PH categorisation highlights the necessity of an optimised approach for each stage of patient management. This requires integrating imaging modalities and incorporating the latest technologic advances. The radiologic community faces new challenges regarding $\mathrm{PH}$ evaluation. One important objective of this position paper is to share current imaging options with $\mathrm{PH}$ clinicians for an optimal use of available resources. Whereas diagnosis and treatment are optimally approached in specialised centres, all radiologists can play a more active role in the early recognition of this disease, helping to reduce the delay in diagnosis. To reach these objectives, this position paper focuses on a series of questions relevant for both nonexpert and expert centres, emphasising noninvasive imaging (e.g. CT, MRI, and nuclear medicine) approaches in a target population of adult patients with $\mathrm{PH}$ (table 2). Specific attention is directed toward imaging of chronic precapillary PH (groups 1, 3, 4, and 5). An expert centre can be defined as a centre fulfilling the criteria of a $\mathrm{PH}$ referral centre as per European Society of Cardiology and European Respiratory Society guidelines (table E1 in appendix E1) [7].

\section{TABLE 1 Updated clinical classification of PH}

\section{Classification}

Group 1: PAH

1.1 Idiopathic $\mathrm{PAH}$

1.2 Heritable $\mathrm{PAH}$

1.3 Drug- and toxin-induced PAH

1.4 PAH associated with:

1.4.1 Connective tissue disease

1.4.2 HIV infection

1.4.3 Portal hypertension

1.4.4 Congenital heart disease

1.4.5 Schistosomiasis

1.5 PAH long-term responders to calcium channel blockers

1.6 PAH with overt features of venous and capillary (PVOD/PCH) involvement

1.7 Persistent $\mathrm{PH}$ of newborn syndrome

\section{Group 2: PH due to left heart disease}

2.1 $\mathrm{PH}$ due to heart failure with preserved LVEF

$2.2 \mathrm{PH}$ due to heart failure with reduced LVEF

2.3 Valvular heart disease

2.4 Congenital/acquired cardiovascular conditions leading to postcapillary $\mathrm{PH}$

Group 3: PH due to lung diseases and/or hypoxia

3.1 Obstructive lung disease

3.2 Restrictive lung disease

3.3 Other lung disease with mixed restrictive/obstructive pattern

3.4 Hypoxia without lung disease

3.5 Developmental lung disorders

Group 4: PH due to pulmonary artery obstructions

4.1 Chronic thromboembolic PH

4.2 Other pulmonary artery obstructions

Group 5: PH with unclear and/or multifactorial mechanisms

5.1 Haematologic disorders

5.2 Systemic and metabolic disorders

5.3 Others

5.4 Complex congenital heart disease

LVEF: left ventricular ejection fraction; $\mathrm{PAH}$ : pulmonary arterial hypertension; $\mathrm{PCH}$ : pulmonary capillary haemangiomatosis; PH: pulmonary hypertension; PVOD: pulmonary veno-occlusive disease. Source: reference [1]. 


\begin{tabular}{|c|c|c|c|c|c|c|c|}
\hline Variable & $\begin{array}{l}\text { Chest } \\
\text { radiography }\end{array}$ & $V / Q$ scan & SPECT/CT V/Q & $\begin{array}{l}\text { Single-energy CT } \\
\text { angiography\# }\end{array}$ & $\begin{array}{l}\text { Dual-energy CT } \\
\text { angiography }\end{array}$ & MRI & $\begin{array}{l}\text { Pulmonary } \\
\text { angiography }\end{array}$ \\
\hline $\begin{array}{l}\text { PH detection } \\
\text { Evaluation of } \\
\text { anatomic } \\
\text { compartments }\end{array}$ & + & - & - & + & + & + & - \\
\hline Lung & + & - & + & +++ & +++ & - & - \\
\hline $\begin{array}{l}\text { Cardiac } \\
\text { chambers }\end{array}$ & + & - & - & ++ & ++ & +++ & - \\
\hline $\begin{array}{l}\text { Pulmonary } \\
\text { vessels }\end{array}$ & + & + & + & +++ & ++++ & ++ & ++ \\
\hline Mediastinum & - & - & - & +++ & +++ & +++ & - \\
\hline $\begin{array}{l}\text { Assessment of } \\
\mathrm{PH} \text { aetiology }\end{array}$ & ++ & ++ & ++ & +++ & ++++ & ++ & ++ \\
\hline $\begin{array}{l}\text { General } \\
\text { strengths }\end{array}$ & $\begin{array}{l}\text { Readily } \\
\text { available }\end{array}$ & $\begin{array}{c}\text { Screening for chronic } \\
\text { thromboembolic PH; } \\
\text { SPECT (tomographic V/Q) } \\
\text { currently replacing planar } \\
\text { V/Q }\end{array}$ & $\begin{array}{l}\text { Combined } \\
\text { evaluation of lung } \\
\text { parenchyma with } \\
\text { lung perfusion }\end{array}$ & $\begin{array}{l}\text { Excellent evaluation of } \\
\text { aetiologies of } \mathrm{PH}\end{array}$ & $\begin{array}{l}\text { Assessment of } \\
\text { anatomy and lung } \\
\text { perfusion (iodine } \\
\text { maps) in a single } \\
\text { test }\end{array}$ & $\begin{array}{l}\text { No radiation; } \\
\text { excellent evaluation of } \\
\text { cardiac function and } \\
\text { pulmonary flow in one } \\
\text { examination }\end{array}$ & $\begin{array}{c}\text { Planning of } \\
\text { endovascular } \\
\text { treatment (PEA, } \\
\text { BPA) }\end{array}$ \\
\hline Weaknesses & $\begin{array}{l}\text { Limited role in } \\
\text { the assessment } \\
\text { of aetiology }\end{array}$ & $\begin{array}{l}\text { Need further imaging to } \\
\text { assess the cause of } \mathrm{PH} ; \\
\text { interpretive limitations in } \\
\text { test patients with } \\
\text { comorbid conditions }\end{array}$ & $\begin{array}{l}\text { Lung assessment } \\
\text { limited; needs more } \\
\text { validation; radiation } \\
\text { dose added with use } \\
\text { of CT }\end{array}$ & $\begin{array}{c}\text { Limited haemodynamic } \\
\text { assessment; limited } \\
\text { evaluation of distal } \\
\text { pulmonary arteries } \\
\text { (beyond subsegmental } \\
\text { level) }\end{array}$ & $\begin{array}{l}\text { Needs validation } \\
\text { for all dual-energy } \\
\text { CT technologies }\end{array}$ & $\begin{array}{l}\text { Limited in evaluation } \\
\text { of lung parenchyma; } \\
\text { not widely available; } \\
\text { more technical } \\
\text { expertise needed }\end{array}$ & $\begin{array}{l}\text { Absence of } \\
\text { perivascular } \\
\text { structure } \\
\text { evaluation; } \\
\text { invasive test }\end{array}$ \\
\hline $\begin{array}{l}\text { Average effective } \\
\text { radiation } \\
\text { exposure } \\
\text { [mSv] }\end{array}$ & 0.05 & 2.2 & $2.6-3.5$ & $2-5$ & $3-5$ & None & $10-30$ \\
\hline
\end{tabular}

Modified from reference [8]. BPA: balloon pulmonary angioplasty; PEA: pulmonary endarterectomy; PH: pulmonary hypertension; V/Q scan: ventilation-perfusion scintigraphy. -: no utility; +: limited utility; ++: moderately useful; +++: useful; ++++: very useful. \# : non-electrocardiogram-gated CT. 


$\begin{array}{ll}\text { BOX 1 } & \text { Abbreviations } \\ \text { BPA } & \text { balloon pulmonary angioplasty } \\ \text { CTEPH } & \text { chronic thromboembolic pulmonary hypertension } \\ \text { ILD } & \text { interstitial lung disease } \\ \text { PA } & \text { pulmonary artery } \\ \text { PAH } & \text { pulmonary arterial hypertension } \\ \text { PAP } & \text { pulmonary artery pressure } \\ \text { PCH } & \text { pulmonary capillary haemangiomatosis } \\ \text { PEA } & \text { pulmonary endarterectomy } \\ \text { PH } & \text { pulmonary hypertension } \\ \text { PVOD } & \text { pulmonary veno-occlusive disease } \\ \text { RV } & \text { right ventricle } \\ \text { V/Q } & \text { ventilation-perfusion }\end{array}$

\section{BOX 2 Key results}

A mean pulmonary artery pressure of greater than $20 \mathrm{mmHg}$ defines pulmonary hypertension (PH)

Pulmonary artery diameter is insufficient as a standalone criterion for $\mathrm{PH}$

Per current guidelines, ventilation-perfusion lung scan is the recommended investigation in patients with $\mathrm{PH}$ to rule out chronic thromboembolic $\mathrm{PH}$

Single-energy CT can provide diagnostic information on $\mathrm{PH}$ aetiology and should play a more important role in the diagnostic strategy

Dual-energy CT combines morphologic information with lung perfusion (i.e. iodine maps), which has the potential of increasing CT diagnostic capabilities

Besides lifelong anticoagulation, pulmonary endarterectomy is the treatment of choice in patients with proximal obstructing lesions; for inoperable cases, medical therapy with or without balloon pulmonary angioplasty is recommended

Cardiac MRI has become the reference standard to determine right ventricular function in patients with $\mathrm{PH}$ of various aetiologies; several MRI-derived variables, such as right ventricular ejection fraction, provide independent prognostic information

\section{Materials and methods}

A working group was formed from within the Fleischner Society based on expertise in the imaging (M. Remy-Jardin, M.L. Schiebler, A.N.C. Leung, J.M. Wild, M.M. Hoeper, P.O. Alderson, L.R. Goodman, J. Mayo, L.B. Haramati, Y. Ohno, E.J.R. van Beek, D.A. Lynch and G.D. Rubin) and/or management of patients with PH (M.M. Hoeper, M. Humbert and P. Thistlethwaite) as well as experience with methodologies of systematic reviews (C.J. Ryerson). A librarian also was included (S.L. Knight). The working group identified five key questions that focused on the utility of CT, MRI, and nuclear medicine in the evaluation of $\mathrm{PH}$ (appendix E2).

\section{Overview of modalities for imaging $\mathrm{PH}$}

Noninvasive imaging modalities used in the assessment of patients with suspected or established $\mathrm{PH}$ are transthoracic Doppler echocardiography, chest radiography, CT, radionuclide ventilation-perfusion (V/Q) lung scintigraphy, and MRI. Table 2, modified from AsCHA et al. [8], summarises their relative strengths and weaknesses. Transthoracic Doppler echocardiography-the most widely used noninvasive screening tool in $\mathrm{PH}$-will not be reviewed in this position paper because it has been covered in recent international guidelines and proceedings of the World Symposium on PH [7, 9].

Whereas chest radiography is not specifically reviewed in this article, its role in advanced $\mathrm{PH}$ deserves specific mention. In a majority of patients with idiopathic $\mathrm{PAH}$, chest radiography is abnormal at the time of diagnosis, showing central pulmonary arterial dilatation that contrasts with pruning of peripheral blood vessels [7]. Right atrium and right ventricle (RV) enlargement may be seen in more advanced cases [7]. Chest radiography may assist in differential diagnosis of $\mathrm{PH}$ by showing signs suggesting lung disease or pulmonary venous congestion due to left heart disease. It may also help in distinguishing between arterial and venous $\mathrm{PH}$ by respectively demonstrating increased and decreased artery-to-vein ratio [7]. Overall, the degree of $\mathrm{PH}$ in any given patient does not correlate with the extent of radiographic abnormalities. As for electrocardiography, a normal chest radiograph does not exclude $\mathrm{PH}$ [7]. 


\section{Question 1: Is noninvasive imaging capable of identifying PH?}

In patients with $\mathrm{PH}$, increased PAP results in structural, functional, and haemodynamic changes assessable with imaging. Numerous CT [10-14] and MRI studies [15-18] have shown that absolute or relative size of the pulmonary artery (PA) can be directly correlated with PAP as measured with right heart catheterisation. However, the diagnostic performance of static PA dimensions on routine chest CT studies to identify $\mathrm{PH}$ has yielded inconsistent results, with areas under the receiver operating characteristic curve, or AUCs, ranging from 0.55 to 0.93 for PA diameter and $0.73-0.95$ for PA diameter-to-aorta ratio (hereafter, PA ratio), respectively [10-13, 19-22].

This variability likely reflects heterogeneity arising from differences in diagnostic criteria and reference standards used to establish the presence of $\mathrm{PH}$, lack of standardisation in vascular measurement techniques and applied cutoff values, and nonuniform patient selection practices resulting in study populations that differed in chronicity and severity of $\mathrm{PH}$. Optimised selection of PA size cutoffs to discriminate between the presence or absence of $\mathrm{PH}$ would ideally incorporate knowledge of the distribution of values in the healthy population. Older age, male sex, and higher body surface area are each correlated with larger PA size and PA ratio decreases with increasing age [23, 24]. Moreover, the PA ratio is not applicable in the case of aortic dilatation. Based on measurements obtained from electrocardiogram-gated chest CT scans in 706 healthy Americans, the 90th percentile cutoffs for normal PA diameter were $28.9 \mathrm{~mm}$ for men and $26.9 \mathrm{~mm}$ for women; corresponding 90th percentile cutoff for PA ratio was 0.91 for both sexes [23]. Similarly derived 90th percentile PA diameter and PA ratio cutoffs observed in 813 healthy Koreans were $31.3 \mathrm{~mm}$ and 1.05 for men and $29.6 \mathrm{~mm}$ and 1.03 for women, respectively [24].

Both duration and severity of elevated PAP likely affect the degree of associated PA dilatation [15]. PA diameter is unreliable for detection of $\mathrm{PH}$ in diseases such as acute respiratory distress syndrome in which the duration of PAP elevation is relatively short [19]. Chronic mild elevation of PAP, as typically occurs in $\mathrm{PH}$ due to lung diseases such as interstitial lung disease (ILD) and chronic obstructive pulmonary disease, may also be difficult to accurately diagnose due to overlap in PA size measurements between normal and these diseased populations [25-29]. In a prospective study of 134 patients suspected of having PH [30], PA diameter and PA ratio showed poor (AUCs of 0.65 and 0.64 ) and fair (AUCs of 0.73 and 0.78) performance in detection of $\mathrm{PH}$ in patients with and without advanced ILD, respectively. Discriminatory performance of vascular measurements in this prospective study of patients with mild to moderate $\mathrm{PH}$ (mean PAP, $32.3 \mathrm{mmHg}$ in ILD and $37.9 \mathrm{mmHg}$ in non-ILD PH groups) was notably inferior to performance observed in a retrospective study of 489 patients with higher mean PAP (mean PAP of the whole cohort, $41 \mathrm{mmHg}$; mean PAP of patients with ILD, $41 \mathrm{mmHg}$; mean PAP of non-ILD patients, $43 \mathrm{mmHg}$ ) referred to a $\mathrm{PH}$ centre [16]. In this latter study, AUCs for PA diameter and PA ratio were 0.87 and 0.80 in ILD group and 0.83 and 0.79 in non-ILD group, respectively. Applied cutoffs of PA diameter greater than $29 \mathrm{~mm}$ and greater than $30 \mathrm{~mm}$ in ILD and non-ILD groups yielded corresponding sensitivities of $75 \%$ and $76 \%$ and specificities of $89 \%$ and $73 \%$, respectively. The addition of ventricular measurements such as right and left ventricular diameter greater than or equal to 1.2 on contrast-enhanced chest CT examinations may improve diagnostic performance, particularly in patients with moderate to severe $\mathrm{PH}[21]$.

TRUONG et al. [31] derived and validated a CT-based four-tier severity classification system of PA diameter and PA ratio (each measurement subdivided as normal, mild, moderate, and severe) for the diagnosis of $\mathrm{PH}$, designed to maximise test sensitivity and specificity at low and high cutoff values, respectively. Using sex-specific normal cutoffs for PA diameter in men $(\leqslant 29 \mathrm{~mm})$ and women $(\leqslant 27 \mathrm{~mm})$ and a sex-neutral $\mathrm{PA}$ ratio (0.9), sensitivities for the normal tier in the derivation cohort were $99 \%$ and $93 \%$ with corresponding specificities of $57 \%$ and $65 \%$ and negative predictive values of $96 \%$ and $86 \%$, respectively. In the most severe tier, PA diameter and PA ratio cutoff values of greater than $34 \mathrm{~mm}$ and greater than 1.1 yielded specificities of $98 \%$ and $100 \%$ with corresponding sensitivities of $65 \%$ and $50 \%$ and positive predictive values of $98 \%$ and $100 \%$, respectively. It is important to recognise that these results, using cutoff values from the four-tier classification system, were found in a high-risk, retrospectively enrolled population of 228 patients who underwent evaluation for suspected $\mathrm{PH}$ at a tertiary care medical centre and were eventually found to have a high prevalence of disease $(60 \%)$; those with $\mathrm{PH}$ had clearly elevated mean PAP (45 mmHg). Diagnostic accuracy of these PA size measurements at chest CT to diagnose PH in practice settings where the prevalence and severity of disease is likely to be lower would benefit from further validation in prospective studies. Table 3 shows an empirical guide to the potential relevance of a dilated PA when found as an incidental finding with differing thresholds according to the risk of $\mathrm{PH}$. Figures E1 and E2 illustrate the need to integrate the clinical context in the interpretation of PA diameter in clinical practice. 
TABLE 3 Proposed thresholds of PA diameter for suggesting underlying PH according to the clinical context

\begin{tabular}{lcccc} 
CT criteria & \multicolumn{3}{c}{ Incidental finding } & Suspected \\
\cline { 2 - 4 } & $\begin{array}{c}\text { Populations with } \\
\text { low risk of } \mathbf{P H}^{\#}\end{array}$ & $\begin{array}{c}\text { Populations with } \\
\text { intermediate risk of } \mathbf{P H}^{\mathbb{\pi}}\end{array}$ & $\begin{array}{c}\text { Populations with } \\
\text { high risk of } \mathbf{P H}^{+}\end{array}$ & PH \\
PA diameter (mm) & $>34$ & $>32$ & $>30$ & Any size \\
PA diameter-to-aorta & $>1.1$ & $>1.0$ & $>0.9$ & Any
\end{tabular}

Note: Pulmonary artery (PA) measurements for diagnosis of pulmonary hypertension (PH) are unreliable in patients with congenital heart disease including aortic or pulmonic valvular stenosis, arteriovenous malformations, connective tissue disorders such as Marfan syndrome and Ehlers-Danlos syndrome, vasculitides such as Behcet disease and Takayasu arteritis, and idiopathic/mycotic/traumatic aneurysms or pseudoaneurysms. " : no known risk factors; estimated risk of PH less than $1 \%$. ": estimated risk of PH 1$10 \%$; predisposing conditions include connective tissue disease (apart from systemic sclerosis), portal hypertension, prior pulmonary embolism, human immunodeficiency virus infection, thalassemia, schistosomiasis. ${ }^{+}$: estimated risk of $\mathrm{PH}$ greater than $10 \%$; predisposing conditions include left heart disease, chronic obstructive pulmonary disease, interstitial lung disease, obstructive sleep apnea, systemic sclerosis, chronic kidney disease requiring dialysis, congenital heart disease, sickle cell disease.

At MRI, dynamic PA size measurements (PA diameter, PA ratio, PA area, and PA relative area change) show comparable performance to CT-based measurements in diagnosis of $\mathrm{PH}$ with AUCs ranging from 0.71 to $0.93[15-18,32]$. Overall, diagnostic performance of MRI is superior to that of non-electrocardiogram-gated CT due to its ability to assess and quantify additional structural and functional cardiovascular metrics indicative of increased PAP and pulmonary vascular resistance. These include interventricular septal angle, RV ejection fraction, ventricular mass index, and PA pulsatility, each of which has been reported to show good to excellent discrimination (AUCs, 0.87-0.99) between patients with and patients without $\mathrm{PH}$ [32-37]. All of these measurements are also attainable with electrocardiogram-gated CT, but their use for the assessment of $\mathrm{PH}$ has not been studied except in small cohorts [38]. Quantitation of pulmonary blood flow dynamics at MRI has also been reported to have diagnostic value [39-42]; in a study of 233 patients suspected of having $\mathrm{PH}$ (mean PAP, $45 \mathrm{mmHg}$ in $\mathrm{PH}$ subgroup), a simple visual score of artefacts arising from abnormally slow pulmonary blood flow imaged by using an electrocardiogram-gated spin-echo double inversion-recovery "black blood" sequence outperformed PA diameter and PA ratio (AUC of 0.86 versus 0.81 and 0.75 ) in diagnosis of $\mathrm{PH}$ [35]. By using regression analysis, JoHNs et al. [43] have developed and validated two multiparametric cardiac MRI models of similar performance (AUCs of 0.95 and 0.93 ) that included interventricular septal angle, ventricular mass index, and either extent of black blood slow flow (model 1) or diastolic PA area (model 2). Sensitivity, specificity, positive predictive value, and negative predictive value of model 1 for diagnosis of $\mathrm{PH}$ in their validation cohort of 303 patients suspected of having $\mathrm{PH}$ (disease prevalence, 85\%; mean PAP, $42 \mathrm{mmHg}$ ) were 93\%, 79\%, 96\%, and 67\%, respectively. Practical considerations for assessing $\mathrm{PH}$ in the clinic are detailed in appendix E3.

\section{Question 2: What is the role of imaging in establishing the cause of PH?}

In the stratification of potential causes of $\mathrm{PH}, \mathrm{V} / \mathrm{Q}$ lung scintigraphy plays a key role to screen for CTEPH while CT is a major imaging tool, traditionally indicated for further evaluation of the underlying cause of $\mathrm{PH}[7,9]$. This section provides an updated approach to the technologic developments and current clinical approach to $\mathrm{PH}$ management in routine clinical practice.

\section{V/Q scintigraphy}

Current guidelines state that a V/Q lung scan should be performed in patients with $\mathrm{PH}$ to rule out CTEPH $[7,44]$. Other than this one indication, V/Q lung scanning is rarely useful in elucidating a cause of $\mathrm{PH}$. The recognition of CTEPH is based on approaches similar to those used for the detection of acute pulmonary embolism, utilising chest radiography with combined V/Q lung scanning techniques. The identification of lung segments and/or subsegments without perfusion but preserved ventilation (i.e. mismatch) is highly suggestive of $\mathrm{PE}$ [45]. In patients with $\mathrm{PH}$ and a clear chest radiograph, a normal-near normal V/Q lung scan virtually excludes CTEPH with a sensitivity of $90 \%-100 \%$ and a specificity of $94 \%-$ $100 \%[46,47]$. The presence of mismatched perfusion defects is compatible with CTEPH and requires further work-up in an expert centre (figure 1) $[6,7,44]$.

This importance of a definitive end point in $\mathrm{PH}$ requires unequivocal lung scan interpretations. Recently, STEIN et al. [48] and MetTer et al. [49] studied lung scintigraphy for suspected acute pulmonary embolism 


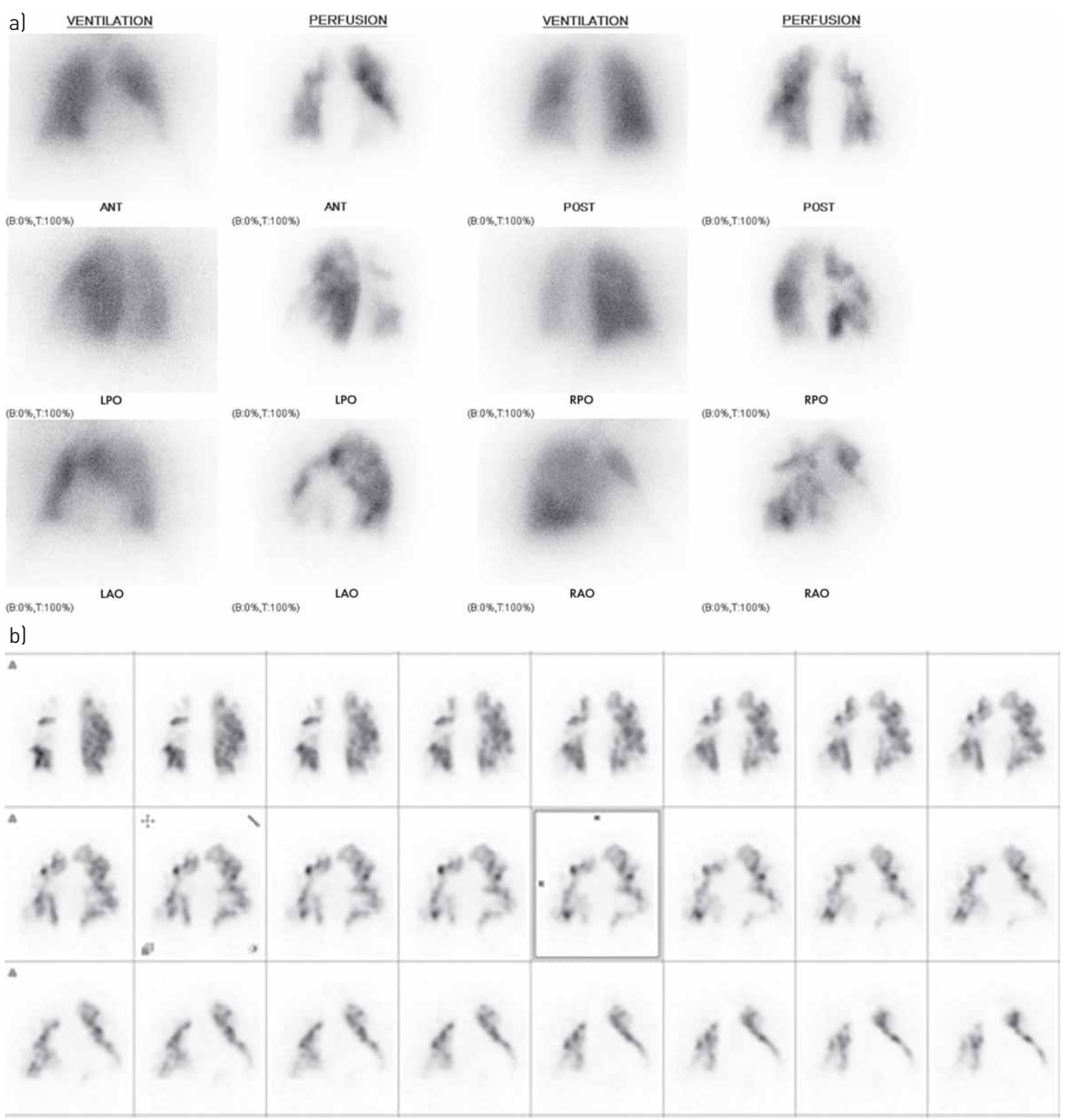

FIGURE 1 Ventilation-perfusion scintigraphy in a 78-year-old woman with normal chest radiograph referred for clinical suspicion of chronic thromboembolic pulmonary hypertension (CTEPH). a) Planar ventilation (81m-krypton) and perfusion ( $99 \mathrm{~m}$-technetium macroaggregate albumin) imaging shows multiple segmental and subsegmental defects in normally ventilated lungs, highly suggestive of CTEPH. b) SPECT perfusion images provide detailed analysis of perfusion defects in coronal plane. ANT: anterior; LAO: left anterior oblique; LPO: left posterior oblique; POST: posterior; RAO: right anterior oblique; RPO: right posterior oblique.

in general patient populations and advocated for the replacement of probability-based V/Q lung scan interpretations with a more definitive approach, that is, normal, nondiagnostic or abnormal for PE. The same strategy is recommended in the diagnostic work-up of patients with PH. Increased sensitivity for detecting acute pulmonary embolism is provided by using SPECT perfusion lung scintigraphy compared with planar lung scintigraphy [50-52]. The increased sensitivity for PE at SPECT is primarily related to the detection of smaller perfusion defects such as those caused by subsegmental acute emboli. Indeterminate results are less frequent than with planar scanning. A recent study [53] found SPECT perfusion scans to be more sensitive than planar V/Q scans in identifying obstructed vascular segments in CTEPH. Mismatched perfusion defects similar to those seen in CTEPH have been reported on V/Q SPECT scans in $10 \%$ of PAH and $7.1 \%$ of patients with pulmonary venous and capillary hypertension (pulmonary veno-occlusive disease (PVOD)/pulmonary capillary haemangiomatosis (PCH)) [54]. In the majority of patients with $\mathrm{PAH}, \mathrm{V} / \mathrm{Q}$ scintigraphy is normal or without significant abnormalities and cannot help discriminating PVOD/PCH from idiopathic PAH [55]. When abnormal, the most frequent pattern in patients with $\mathrm{PVOD} / \mathrm{PCH}$ is that of patchy perfusion defects with similar perfusion characteristics depicted on dual-energy CT lung perfusion images [56]. SPECT lung scintigraphy was compared with contrast-enhanced perfusion MRI in a series of 74 patients with PH: 30 of the patients had 
CTEPH and 10 had chronic thromboembolic disease without PH [57]. SPECT and MRI showed virtually identical sensitivity (97\% SPECT, 100\% MRI) for PE. The only patient missed with SPECT perfusion scintigraphy had distal CTEPH. SPECT/CT has been widely evaluated in the scintigraphic evaluation of $\mathrm{PE}$ but not extensively in the diagnostic approach of CTEPH.

It is worth noting that, if the perfusion agent (i.e. technetium-labelled particles of macroaggregates of human albumin, or Tc-99m MAA) is detected beneath the diaphragm, this may signal the presence of a right-to-left cardiac shunt. Plainly, intracardiac shunts are an important cause of PAH. If cardiac defects have a component of right-to-left flow, some Tc-99m MAA particles will bypass the lung and localise in other organs (e.g. liver, kidneys, brain). More definitive diagnosis of such shunts is provided by obtaining a lateral view of the cranium, which will show Tc-99m intracerebral activity. Subdiaphragmatic Tc-99m MAA activity also has been seen in patients with hepatic failure who have macroscopic intrapulmonary shunts (hepatopulmonary syndrome), in patients with congenital pulmonary arteriovenous malformations (Osler-Weber-Rendu disease), and in patients who have undergone cavopulmonary anastomotic surgery.

\section{Role of single-energy CT}

Fast scanning, excellent spatial and temporal resolution, and ability to comprehensively evaluate the cardiopulmonary structures are some of the distinct features of CT. Depending on the clinical context, both noncontrast and contrast-enhanced CT examinations can be considered. Noncontrast chest CT is a powerful noninvasive test for all situations in which lung disease (e.g. chronic obstructive pulmonary disease, ILD) is responsible for the haemodynamic syndrome (i.e. group $3 \mathrm{PH}$ ). Several systemic and metabolic disorders described in the subgroup of $\mathrm{PH}$ with unclear and/or multifactorial mechanism (group 5) can also benefit from a noncontrast chest CT examination, such as sarcoidosis, pulmonary Langerhans cell histiocytosis, and neurofibromatosis. Noncontrast CT examinations can also show features depictable in group $1 \mathrm{PH}$. In PAH, pulmonary microvasculopathy can lead to subtle changes at CT, including centrilobular micronodules, peripheral neovascularisation, and lobular areas of ground-glass attenuation. The presence of nodular ground-glass opacities, septal lines, and adenopathy is highly suggestive of $\mathrm{PAH}$ with overt features of venous and capillary (PVOD/PCH) involvement (figure 2) $[58,59]$.
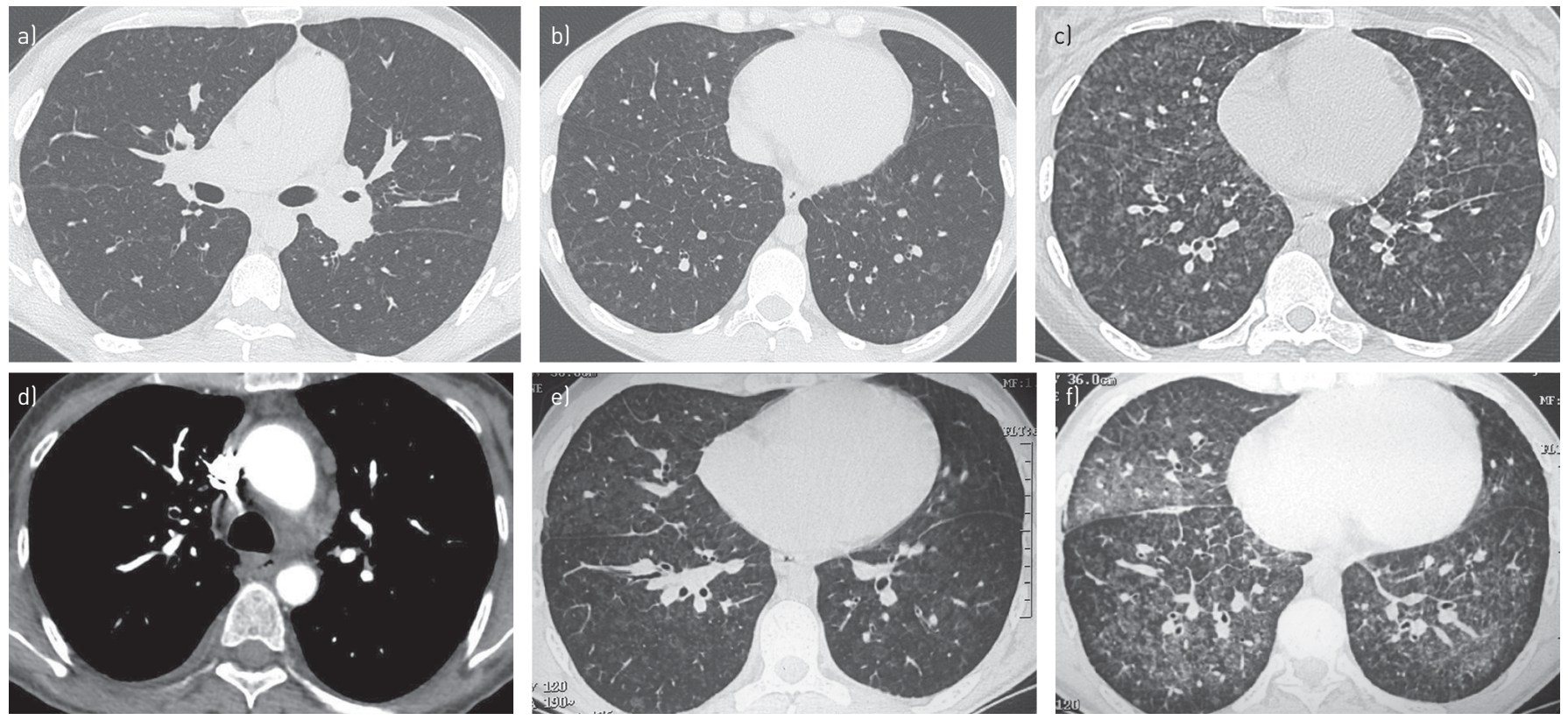

FIGURE 2 Images show CT findings in patients with pulmonary hypertension due to presence of pulmonary veno-occlusive disease (PVOD)/ pulmonary capillary haemangiomatosis (PCH). a) Transverse CT section at level of right and left main bronchi from noncontrast examination in a 45-year-old woman shows centrilobular lung nodules in both lungs with enlarged left hilum due to underlying lymphadenopathy. b) Same examination as that shown in (a). Transverse CT section obtained at level of lower lobes shows bilateral centrilobular nodules seen and thin septal lines in right lower lobe. c) Transverse CT section at level of lower lobes from noncontrast examination obtained in a 51-year-old woman shows profuse nodular ground-glass opacities. d) Transverse CT section at level of carina from chest CT angiographic study obtained in a 35-year-old woman shows mediastinal lymphadenopathy. e) Transverse CT section at level of lower lobes from noncontrast examination in a 61-year-old woman before treatment. Note presence of centrilobular nodules in both lungs. f) Transverse CT section at same level as that shown in (e) (same patient); noncontrast chest CT examination obtained 6 weeks after initiation of endothelin receptor antagonist shows CT features of pulmonary oedema. 

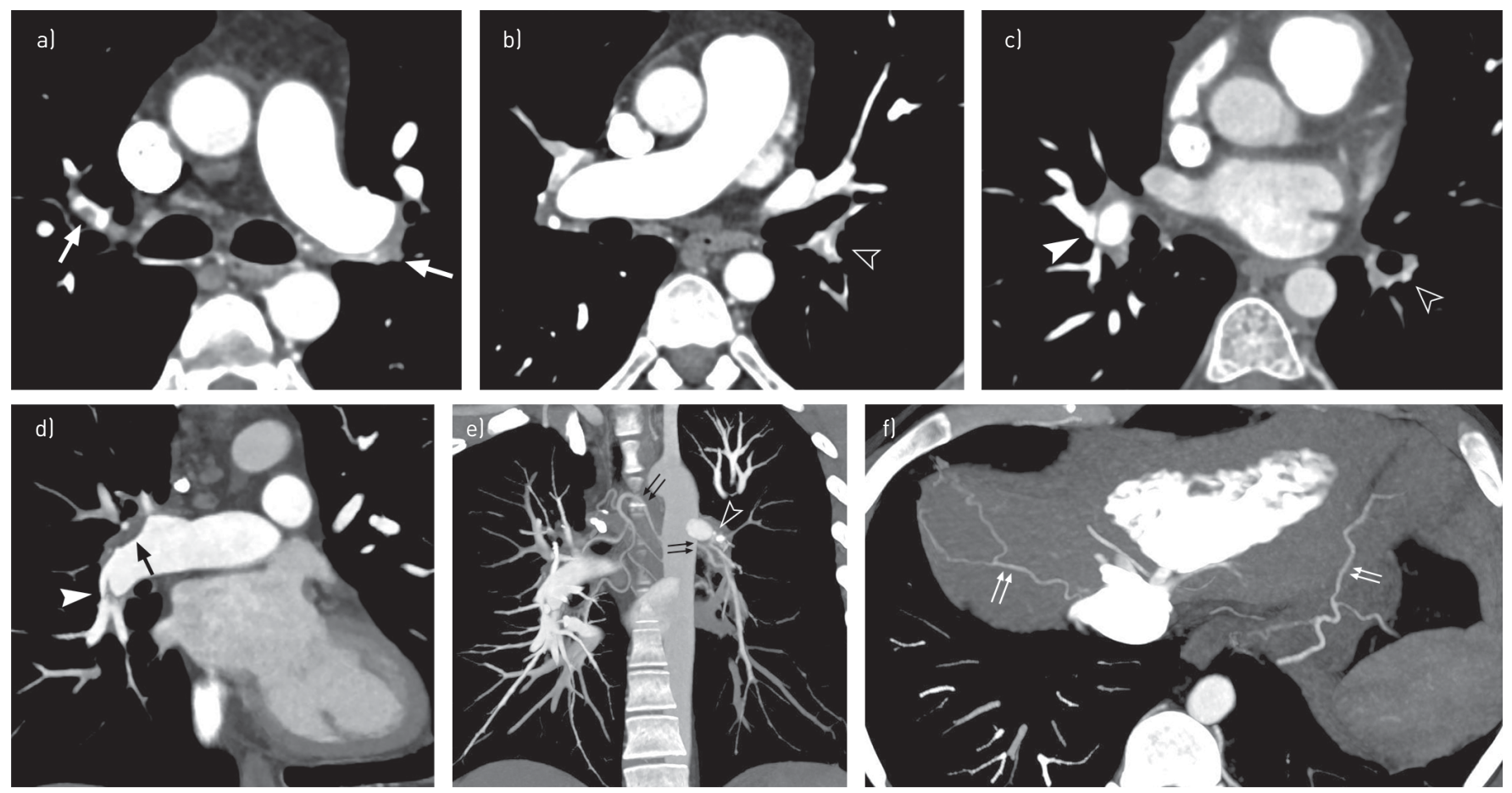

FIGURE 3 Images show chest CT angiography in a 25-year-old man with persistent dyspnoea 1 year after bilateral acute pulmonary embolism (PE), suggestive of interim development of chronic thromboembolic pulmonary hypertension. a-c) Transverse CT sections and d and e) maximum intensity projections in coronal oblique and f) transversal views show numerous vascular features of chronic PE including partial filling defects (single white arrows and single black arrows), endoluminal band and web (white arrowheads), and severely stenosed pulmonary arteries (black arrowheads). Presence of systemic collateral supply from enlarged bronchial arteries (double black arrows in (e) and inferior phrenic arteries (white double arrows in ( $f$ )). Reperfusion of left interlobar pulmonary artery beyond its obstruction (black arrowhead in (e)) by ipsilateral enlarged bronchial arteries.

Contrast-enhanced chest CT is the second CT-based approach that can be used to elucidate the aetiology of $\mathrm{PH}$. While morphologic changes depictable in $\mathrm{PH}$ aetiologies previously quoted can be similarly identified, the principal benefit of contrast-enhanced CT is for the detection of CTEPH (group 4), the diagnosis of which relies not only on the depiction of vascular signs of chronic obstruction of the PAs (figure 3), but also for diagnosing less common entities such as fibrosing mediastinitis (group 5) (figure 4) and intracardiac shunts, patent ductus arteriosus, and abnormal pulmonary venous return that may be missed with echocardiography (group 1). The absence of morphologic abnormalities at the level of cardiovascular structures and assessable PAs raises the possibility of PAH (group $1 \mathrm{PH}$ ).

In the current guidelines [7], there is a distinction between CT angiography and high-resolution CT (i.e. noncontrast CT), the former being indicated in the work-up of patients with CTEPH and the latter
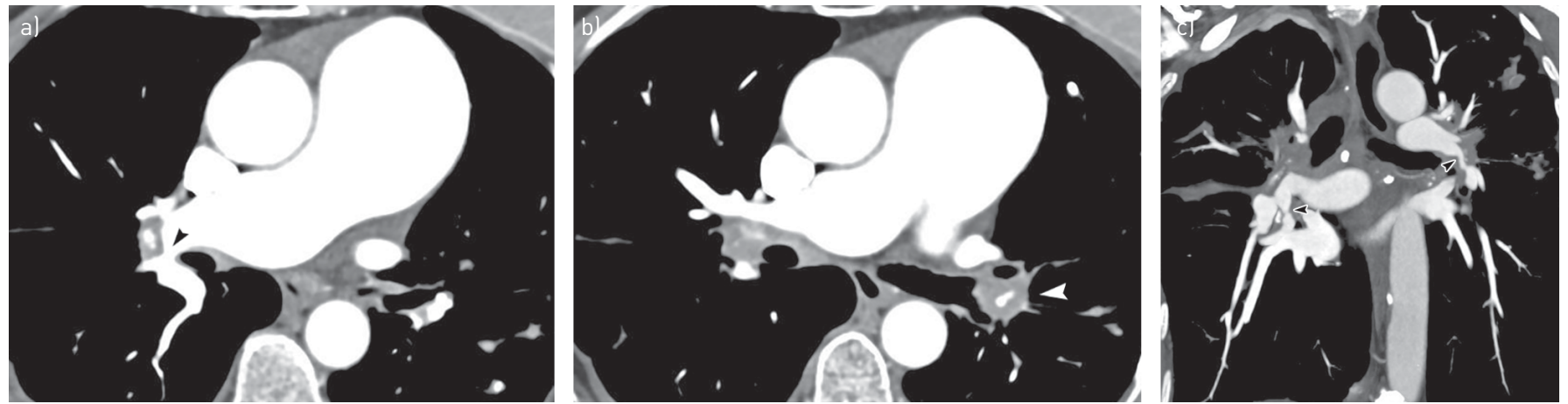

FIGURE 4 Images show chest CT angiography in a 69-year-old woman with previous history of silicosis, responsible for fibrosing mediastinitis and subsequent development of pulmonary hypertension (PH) (group $5 \mathrm{PH}$ ). a and b) Transverse CT sections and c) coronal oblique reformation shows severe stenosis of right and left interlobar pulmonary arteries (arrowheads) by silicotic hilar adenopathy. Diameter of both arterial sections does not exceed $5 \mathrm{~mm}$, responsible for pulmonary hypertension with marked dilatation of mediastinal pulmonary arteries. 
TABLE 4 CT features of acute and chronic obstruction of pulmonary arteries

\begin{tabular}{lll} 
CT Features & Acute PE & Chronic PE \\
\hline Mediastinal images & & Yes \\
Partial filling defects & Yes & Yes \\
Complete filling defects & Yes & Yes \\
Arterial retraction & & Yes \\
Reperfusion channels & & Yes \\
Webs, bands & & Yes \\
Focal stenosis & & Yes \\
Enlarged bronchial arteries & & Yes \\
Enlarged nonbronchial & & Yes \\
systemic arteries & Yes (effusion) & \\
Pleural abnormalities & & Yes (nonspecific fibrotic \\
Lung images & Yes (subpleural, wedge-shaped & infiltration/cysts) \\
Lung infarction/sequelae & consolidation) & Yes (adjacent to severely \\
Bronchial dilatation & & stenosed arteries) \\
Mosaic perfusion & & Yes
\end{tabular}

PE: pulmonary embolism.

recommended in all patients with $\mathrm{PH}$. The guidelines acknowledge the important role for $\mathrm{CT}$ in patient management once the cause of $\mathrm{PH}$ has been recognised, but not in the triage of patients between CTEPH and non-CTEPH. This situation reflects the long-standing influence of a study from TunARIU et al. [46] in which the accuracy of an early multidetector CT technology was compared with that of V/Q scanning. In what is now considered suboptimal and outdated CT technology, CT angiography demonstrated high specificity (99.3\%) but low sensitivity (i.e., 51.3\%) for CTEPH. A recent meta-analysis [60] evaluated the diagnostic accuracy of CT for CTEPH, which documented the limited diagnostic value of four- and eight-row multidetector CT technology compared with scanners ranging from 64-row multidetector CT to recent developments such as 320-row CT or dual-source CT [47, 61, 62]. In the latter category of equipment, the pooled sensitivity was $99 \%$ and the specificity was $97 \%$, leading the authors to conclude that CT could become the standard for CTEPH screening. Besides technologic considerations, a current limitation of $\mathrm{CT}$ angiography in the diagnostic approach to $\mathrm{PH}$ is based on the variable expertise among radiologists in identifying the CT features of chronic thromboembolic disease and accordingly, education and training are clearly needed in this area. As proposed in table 4, a structured examination for specific imaging findings can help in the recognition of CTEPH. In a recent study investigating the diagnosis of underlying CTEPH in association with acute pulmonary embolism, ENDE-VERHAARet al. [63] emphasised the importance of decreased arterial diameter, intravascular webs, and mosaic perfusion as well as dilated bronchial arteries.

\section{Role of dual-energy CT angiography}

Dual-energy CT angiography offers additional diagnostic capabilities when compared with single-energy CT through the creation of iodine maps, which have been considered surrogate markers of lung perfusion. In the clinical context of $\mathrm{PH}$, dual-energy CT lung perfusion has mainly been investigated in CTEPH, showing good agreement with scintigraphy for the detection of perfusion defects [64]. Dual-energy CT-depicted perfusion defects have also shown good correlation with haemodynamic estimates of $\mathrm{PH}$ severity $[65,66]$. Recently, the diagnostic value of dual-energy CT perfusion has been compared with that of V/Q scintigraphy, with sensitivities and specificities ranging from $97 \%$ to $100 \%$ and $86 \%$ to $92 \%$, respectively (figure 5) [61, 62]. Whereas excellent agreement between the two imaging modalities has been reported at a patient level, intermodality agreement at the segmental level varies from modest to moderate $[61,62,64,67]$, owing to differences in their depiction of the distal pulmonary circulation. Perfusion scintigraphy demonstrates the distribution of labelled microspheres at the arteriolar level, while dual-energy CT perfusion captures a systemic phase of lung parenchymal enhancement as systemic-to-pulmonary shunts contribute to perfuse the arterial bed distal to the occluded pulmonary arterial segment $[68,69]$. When an analysis of iodine maps is combined with standard CT images of pulmonary arterial morphology, dual-energy CT has a sensitivity and specificity of $100 \%$ for a diagnosis of CTEPH $[61,62,70]$. These promising results require validation on a larger scale but reinforce the growing importance of modern CT techniques in the diagnosis of CTEPH [71, 72]. Moreover, the patterns of lung 

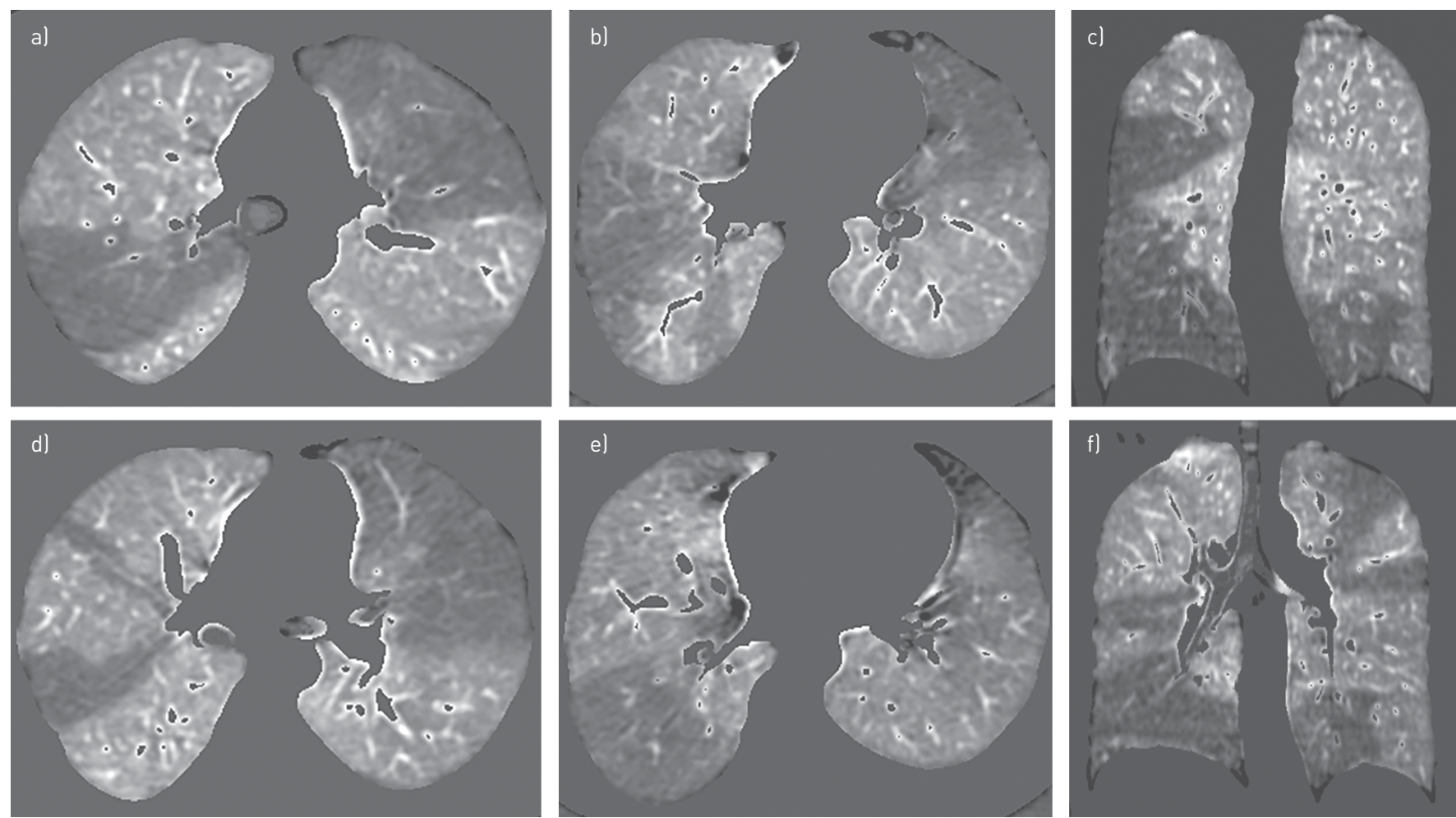

FIGURE 5 Images show dual-source dual-energy CT lung perfusion imaging in a 51 -year-old woman with chronic thromboembolic pulmonary hypertension (CTEPH). a-d) Transverse CT sections and e and f) coronal reformations of dual-energy CT lung perfusion images (window settings: $400 \mathrm{HU} / 40 \mathrm{HU}$ ) show multiple triangular perfusion defects of variable extent in both lungs, highly suggestive of pulmonary thromboembolic disease.

perfusion demonstrated with dual-energy CT can differentiate PAH from peripheral forms of CTEPH, concordant with V/Q scintigraphy [56]. Considerations on the evolving role of CT in the diagnosis approach of PH aetiology are summarised in appendix E4.

\section{Practical considerations for acquiring CT angiograms in patients with PH}

Chest CT angiography is routinely obtained without electrocardiogram synchronisation and consists of thin-section volumetric CT acquisitions. Short breath-hold (1-4 s) acquisition with the highest temporal resolution (i.e. shortest rotation time) avoids respiratory motion artefacts while minimising cardiac motion artefacts. The entire thorax should be scanned with a single volumetric acquisition and re-constructed as contiguous thin sections $(\leqslant 1 \mathrm{~mm})$. Both lung and mediastinal images should be reviewed.

The injection protocol is based on bolus tracking with two options: a) the traditional CT pulmonary angiographic examination, with a region of interest positioned in the pulmonary trunk (threshold for triggering data acquisition, $120 \mathrm{HU}$ ); or b) concurrent opacification of pulmonary and systemic circulations, with a region of interest positioned in the ascending aorta (threshold, $100 \mathrm{HU}$ ). The volume and flow rate are similar to those selected for a standard chest $\mathrm{CT}$ angiographic examination (i.e. 60$80 \mathrm{~mL}$ at $4 \mathrm{~mL} \cdot \mathrm{s}^{-1}$ ). When pulmonary vascular resistance is known to be high, a decrease in flow rate (i.e. $2 \mathrm{~mL} \cdot \mathrm{s}^{-1}$ instead of $4 \mathrm{~mL} \cdot \mathrm{s}^{-1}$ ) is recommended owing to the slow progression of the contrast material through the PAs. In patients with high cardiac output, low-kilovoltage-peak scanning and high flow rate (i.e. $4-6 \mathrm{~mL} \cdot \mathrm{s}^{-1}$ depending on the patient venous access) are recommended to ensure adequate vascular opacification.

The iodine concentration of the contrast material used usually ranges between $300 \mathrm{mg} \mathrm{I}$ per $\mathrm{mL}$ and $350 \mathrm{mg}$ I per mL; it may be increased to $370-400 \mathrm{mg}$ I per $\mathrm{mL}$ when scanning with dual-energy CT to ensure adequate opacification of lung micro-circulation on the postprocessed iodine maps. Scan acquisition during a systemic arterial phase (i.e. region of interest within the ascending aorta) may mask perfusion defects due to enhancement via bronchial and/or nonbronchial systemic collaterals [68]. This scanning condition may influence the pretherapeutic evaluation of perfusion defects, but it does not preclude adequate recognition of pulmonary embolism-type defects on iodine maps $[61,62,70]$. 


\section{Question 3: How does imaging determine the severity and complications of PH? Assessment of RV consequences of $P H$}

During the development of $\mathrm{PH}$, there are important changes to the volume of the RV and the end-systolic and end-diastolic pressures. In the progressive march to cor pulmonale, the end stage of this disease, the RV has a larger end-diastolic volume, the filling pressures increase, the wall thickness increases, the wall stiffness increases, there is more diastolic dysfunction, the pressures needed to open the pulmonary valve eventually become suprasystemic, and the interventricular septum becomes flattened and then bowed toward the left ventricular cavity; this further limits filling of the left ventricle. Over time, the ability of the $\mathrm{RV}$ to cope with both volume and pressure overload is exceeded. Cor pulmonale is a very difficult disorder that results in rapid demise without aggressive management. Even with maximal intravenous pulmonary arteriolar dilation therapies using phosphodiesterase inhibitors (e.g. sildenafil), the deadly nature of cor pulmonale is only temporarily improved.

The severity of $\mathrm{PH}$ in patients with $\mathrm{PAH}$ should be evaluated with a combination of clinical data, including exercise tests, biochemical markers, imaging (echocardiography or MRI), and haemodynamic evaluations [7]. Cardiac MRI is more accurate than echocardiography for the assessment of RV morphology and function and also allows measurement of stroke volume and carbon monoxide. The following cardiac MRI-derived measures are predictive of life expectancy after treatment for $\mathrm{PH}$ : RV end-systolic volume, RV end-diastolic volume index (pooled hazard ratio, 1.06; 95\% CI: 1.00, 1.12; $\mathrm{p}=0.049$ ), RV ejection fraction (pooled hazard ratio, 1.23; 95\% CI: 1.07, 1.41; $\mathrm{p}=0.003$ ), stroke volume index, RV end-systolic volume index (pooled hazard ratio, 1.05; 95\% CI: 1.01, 1.09; p=0.013), global longitudinal strain rate, global circumferential strain rate, and left ventricular end-diastolic index (pooled hazard ratio, 1.16; 95\% CI: 1.00, 1.34; p=0.045) (table E2 in appendix E1) [73-80]. There is variability in these measures partly due to the wide range of individuals studied and a lack of grouping by disease severity. Obviously, individuals with $\mathrm{PH}$ with very mild disease found incidentally will differ markedly from those with severe long-standing $\mathrm{PH}$.

Disease severity (mild, moderate, or severe) is linked with varying levels of derangement in imaging biomarkers. T1 mapping of the myocardium may be uniquely characteristic in PH. In a study of 490 consecutive patients, the $\mathrm{T} 1$ at the RV insertion point discriminated patients with $\mathrm{PH}$ from healthy individuals and was strongly correlated with the interventricular septal angle [81].

\section{Assessment of small-vessel disease}

Small-vessel disease or pulmonary microvasculopathy refers to distal alterations in the pulmonary circulation in the presence of $\mathrm{PH}$. While idiopathic or heritable $\mathrm{PAH}$ is characterised by major remodelling of pre-capillary PAs $(<500 \mu \mathrm{m})$ with plexiform lesions, PVOD/PCH preferentially affects the pulmonary venules and may be associated with pulmonary capillary dilatation and proliferation [2]. In $\mathrm{CTEPH}$, there is growing evidence that, in addition to mechanical obstruction of proximal arteries, some patients develop a pulmonary microvasculopathy affecting the wall of distal muscular PAs out to arterioles and venules $[82,83]$. Their depiction in the pretherapeutic evaluation of CTEPH will be discussed in the following section entitled "Question 4: How should imaging be used to assess CTEPH before treatment?"

In PAH, pulmonary microvasculopathy can lead to subtle changes on CT images as previously described. V/Q scintigraphy will not demonstrate significant abnormalities and may be normal in the majority of patients with PAH. It cannot discriminate PVOD from idiopathic PAH [54]. When abnormal, the most frequent pattern is patchy perfusion defects as also seen on dual-energy CT lung perfusion images [56]. Postprocessing of the pulmonary arterial tree from digital angiograms, CT angiography, and MR angiography can be used to determine fractal geometry. As $\mathrm{PH}$ progresses, the pulmonary arterial tree simplifies, and this simplification can be enumerated by using three-dimensional fractal geometry. When fractal dimension was computed using three-dimensional box counting the distance metric (e.g. the readout of vessel tortuosity), it was found to be correlated with mean PAP (Spearman $r=0.60$ ) [84]. Loss of distal small PA sizes relative to the main PAs is a sign of vessel pruning.

\section{What are the complications of marked PA enlargement in patients with PH?}

Enlargement of the PA in patients with PAH may compress the left main or left anterior descending coronary arteries resulting in decreased coronary blood flow (figure 6). In a study of 765 patients with PAH [85], 121 had angina or anginalike symptoms and 94 patients had abnormal CT angiography based on the relationship between the PA and the left main coronary artery. Left main coronary artery stenosis greater than or equal to $50 \%$ was detected in 48 of 94 patients. The best predictor of left main coronary artery stenosis greater than or equal to $50 \%$ was a PA diameter greater than or equal to $40 \mathrm{~mm}$. When it occurs, left main coronary artery compression is a very serious issue for patients with PAH. The treatment plan used will vary depending on the local expertise. The options include the following: stent placement, 

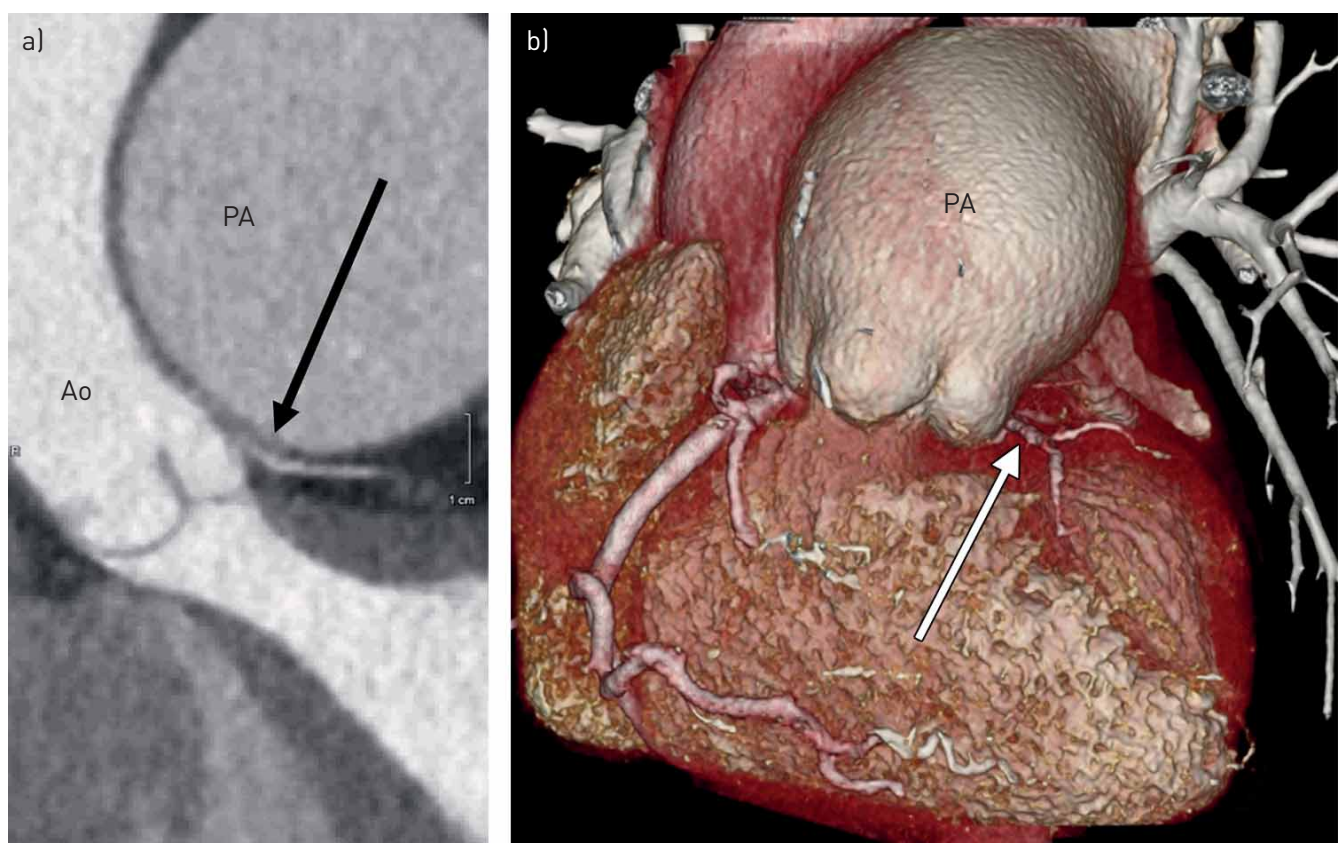

FIGURE 6 Images show long-standing pulmonary arterial hypertension from connective tissue disease (scleroderma) with compression of left main coronary artery. a) Multiplanar reformation of left main coronary artery origin from left sinus of Valsalva shows compression (arrow) by massive pulmonary artery (PA). b) Volume-rendered coronary CT angiography shows enlarged pulmonary trunk (PA) and very small left main coronary artery (arrow). Ao: aorta.

cardiac surgery with bypass grafting, medical management to significantly lower the PAPs, and occasionally lung transplantation. Any surgery must be carefully considered due to the increased operative mortality in patients with $\mathrm{PH}$. There is no single treatment option that always works for this critical issue.

Dissection of the main PA is rare but associated with high mortality. In a recent systematic review [86] of 150 cases reported since 1842, the average age at diagnosis was 45 years with a slight male predominance (1.1:1). The most common clinical presentation of PA dissection was dyspnoea with chest pain. The reported causes were $\mathrm{PH}$, congenital heart disease (overcirculation lesions such as a patent ductus arteriosus), and acquired heart diseases. The pulmonary trunk was the site of dissection in $73 \%$ of cases. The most severe complication of PA dissection was cardiac tamponade from haemopericardium and was observed at autopsy in $84.2 \%$ of cases [86].

\section{Question 4: How should imaging be used to assess CTEPH before treatment? \\ Context}

In $0.6 \%$ to $4.4 \%$ of acute pulmonary embolism, abnormal persistent obstruction of PAs by residual organised thrombi, combined with a variable degree of microscopic vasculopathy, may lead to CTEPH [6, $44,63,82]$. If left untreated, then CTEPH leads to right-heart failure and premature death [6, 7]. The CTEPH medical arsenal has progressed markedly in recent years. As stated in the proceedings of the 6th World Symposium on PH, CTEPH management is a fast-growing field of pulmonary vascular medicine where multimodal, individualised approach to treatment at expert centres with multidisciplinary teams is mandatory $[6,7]$.

\section{Current CTEPH management}

The CTEPH treatment algorithm has been recently proposed by a task force of the 6th World Symposium on $\mathrm{PH}$ (figure 7) [6]. CTEPH treatment decisions in an expert centre involve multidisciplinary teams including experienced surgeons for pulmonary endarterectomy (PEA), interventional radiologists/ cardiologists for balloon pulmonary angioplasty (BPA), radiologists experienced in pulmonary vascular imaging, and pulmonologists/cardiologists with expertise in $\mathrm{PH}$ [6]. Besides indefinite anticoagulation, PEA is the treatment of choice in patients who are deemed operative candidates by having obstructing lesions in the main, lobar, segmental, and subsegmental arteries [6, 7]. However, around half of patients with CTEPH with pulmonary vascular resistance out of proportion to degree of vascular obstruction at imaging may manifest severe distal microvasculopathy and are deemed ineligible for operation [6]. For 
FIGURE 7 Flowchart shows revised treatment algorithm for management of patients with chronic thromboembolic pulmonary hypertension (CTEPH). \#: multidisciplinary Ipulmonary endarterectomy surgeon, pulmonary hypertension expert, balloon pulmonary angioplasty (BPA) interventionist, and radiologist); १: treatment assessment may differ depending on level of expertise; ${ }^{+}$: BPA without medical therapy can be considered in selected cases. Reprinted, with permission, from reference [6].
CTEPH diagnosis

Continue lifelong anticoagulation

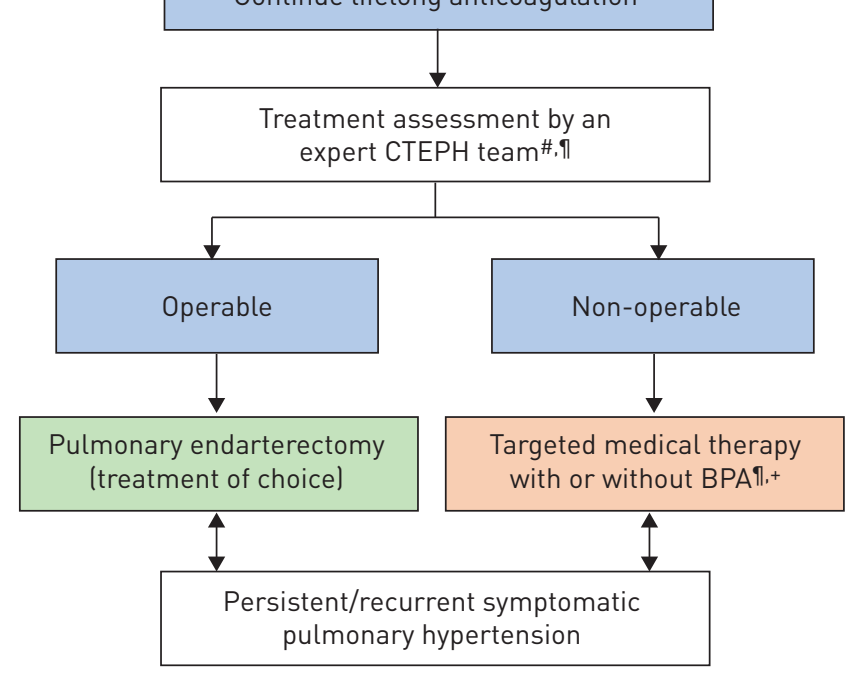

technically inoperable cases, PH medical therapy is recommended with or without BPA [6]. Oral riociguat (a guanylate cyclase stimulator) and subcutaneous treprostinil are currently the only drugs approved for inoperable CTEPH [6, 7].

\section{PEA operability assessment}

Defining the anatomic distribution of CTEPH lesions is essential in this therapeutic approach and certain features are more likely to predict a good surgical outcome [6]. The most important surgical advance has been in redefining the distal limits of endarterectomy $[87,88]$. However, it is important to stress that there is inevitable variation between surgical centres with regard to the suitability of PEA operability [89]. Criteria for inoperability usually include distal PA obstructions, imbalance between increased pulmonary vascular resistance and the number of accessible occlusions suggesting microvascular disease, a pulmonary vascular resistance greater than $1500 \mathrm{dyn} \cdot \mathrm{s} \cdot \mathrm{cm}^{-5}$, and comorbidity [6]. CTEPH lesion type and location can be classified according to the updated University of California San Diego CTEPH surgical classification, which includes the following four levels (figure 8): level 0 (no evidence of thromboembolic disease in either lung), level I (lesions starting in the main PAs with level IC corresponding to complete occlusion of one main PA), level II (lesions starting at the level of lobar arteries or in the main descending PAs), level III (lesions starting at the level of the segmental arteries), and level IV (lesions starting at the level of the subsegmental arteries) [87].

Once the diagnosis of CTEPH is confirmed, CT angiography can be used for assessment of operability (figures 9 and 10) [6]. CT can provide a vascular roadmap for surgical planning and is the best modality for delineation of the proximal extent of the organised thromboembolic material, with good PEA plane correlation [87]. However, it must be emphasised that the use of CT for estimation of surgical suitability requires considerable imaging expertise and is usually best performed by high-volume and experienced institutions $[6,7,90]$. There is a large knowledge gap within the imaging community in the interpretation of CT in CTEPH due to the relative rarity of disease in the general population [6]. The scanning protocol follows the recommendations for chest CT angiography. Analysis of PAs requires combined use of cross-sectional imaging and multiplanar reformations to improve detection of thin webs and bands, focal stenoses, and the display of subsegmental vessels. Digital subtraction angiography, previously considered as the reference standard, has been largely replaced with noninvasive modalities. With advances in distal PEA, the advent of BPA, and a general focus on more distal vascular assessment, conventional digital subtraction angiography may not always be suitable for fine anatomic analysis. For such purposes, selective segmental angiography, cone-beam CT, and electrocardiogram-gated CT may also be considered for precise delineation of distal pulmonary vessels [90, 91].

There is often no clear correlation between the degree of mechanical obstruction found at imaging and the severity of haemodynamic compromise measured with right heart catheterisation [6]. This discrepancy is due to the degree of remodelling affecting small pulmonary vessels [82]. Identifying small pulmonary vascular disease prior to intervention is of major importance because it translates into more severe disease and worse outcomes. Patients with inoperable CTEPH with marked small pulmonary vascular disease are candidates for medical therapy with or without BPA [6]. 

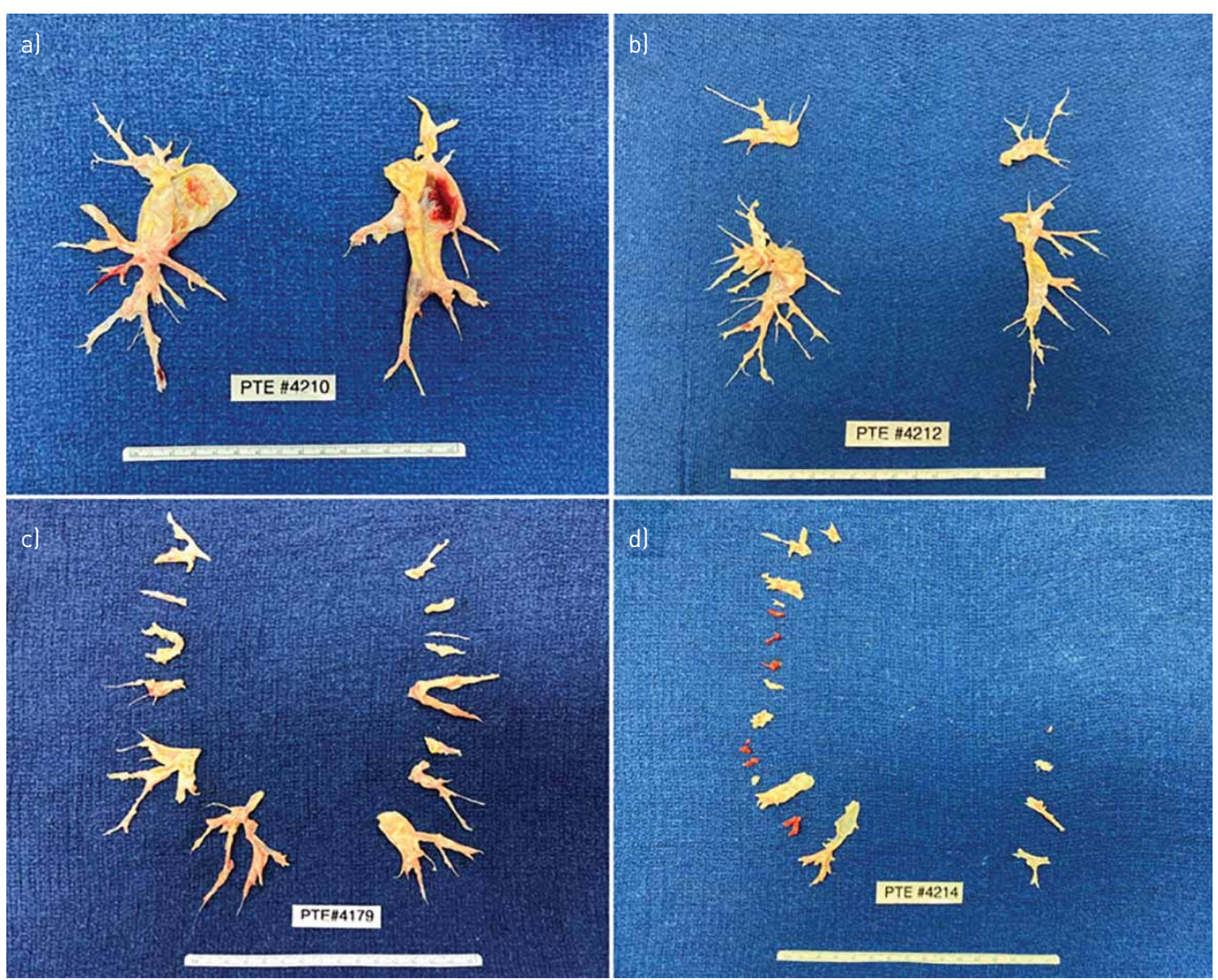

FIGURE 8 Images show updated University of California San Diego chronic thromboembolic pulmonary hypertension (CTEPH) surgical classifications. This figure illustrates location of organised thromboembolic material within pulmonary arteries conditioning their surgical accessibility: levels 1-3 are accessible lesions and level 4 disease is nonoperable. a) Level 1 disease involves one or both main pulmonary arteries. b) Level 2 disease begins at lobar branches or past the takeoff of upper lobe artery. c) Level 3 disease starts at segmental vessels. d) Level 4 disease begins at subsegmental vessels.

The development of hypertrophied bronchial arteries is a well-known feature of CTEPH, reflecting collaterals between the systemic and pulmonary arterial circulation $[6,82,83,92]$. Anastomoses exist between bronchial arteries and precapillary pulmonary arterioles but also between post-capillary venules and small veins [82]. Collateral anastomoses from the systemic circulation have an important role in maintaining perfusion and viability of the ischaemic pulmonary parenchyma downstream of proximal PA obstructions. Some authors have proposed that distal thrombosis can be diffuse when bronchial arteries and anastomoses fail to develop, jeopardising patency of the small pulmonary arterioles [83]. SHIMIZu et al. [92] have reported that the cross-sectional area of bronchial arteries correlated with the central extent of the thromboembolic material from analysis of the CT angiography in patients with CTEPH. In that study, bronchial artery total area in the proximal type of CTEPH was significantly greater than in the distal type. Poor subpleural perfusion in the capillary phase of digital subtraction angiography predicts worse outcomes following PEA in operable CTEPH [93]. Poor subpleural perfusion is defined as less than or equal to $1.5 \mathrm{~cm}$ (approximately one rib width) from the lateral pleura in the capillary phase of digital subtraction angiography on the posterior-anterior views and by lateral views of the dorsal area (figure 11). In such cases, V/Q lung scanning also shows reduced subpleural perfusion with a preserved ventilation [94].

\section{BPA assessment}

BPA is an alternative therapy for patients with inoperable CTEPH [95, 96]. KAWAKAMI et al. [91] have recently reviewed 500 consecutive procedures (1936 lesions) of BPA in 97 patients with CTEPH. The lesion distribution and characteristics evaluated were as follows: type A, ringlike stenosis lesion; type $\mathrm{B}$, web lesion; type C, subtotal lesion; type D, total occlusion lesion; and type E, tortuous lesion. The success rate was higher, and the complication rate was lower, in ringlike stenosis and web lesions. The total occlusion lesions had the lowest success rate. Tortuous lesions were associated with a high complication rate. Optical coherence tomography may be helpful to better characterise endovascular lesions in cases where the diagnosis is unclear. However, experts in BPA rarely use this technique because of the need for 

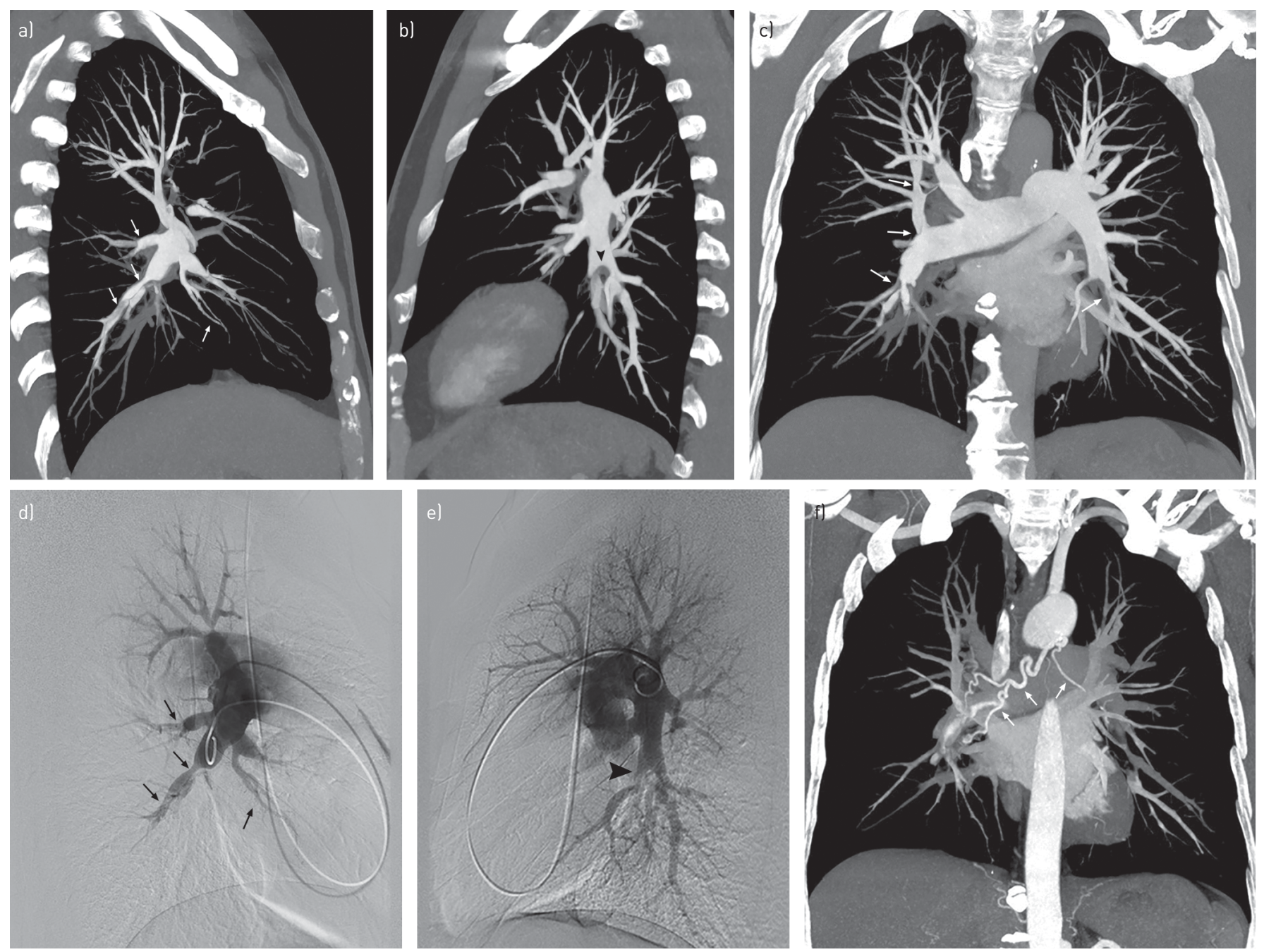

FIGURE 9 a-f) Images show CT angiography and pulmonary angiographic evaluation prior to pulmonary endarterectomy in a 57-year-old patient with central and peripheral chronic thromboembolic pulmonary hypertension (CTEPH). Sagittal views of right (a and b) and left (c and d) pulmonary arteries on CT images and corresponding pulmonary angiograms show numerous vascular features of CTEPH on central and peripheral arteries. In right lung, arrows point to stenosis and poststenosis dilatation, webs, and vessel pruning; in left lung, arrowheads point to a large mural defect and endoluminal webs below. Maximum intensity projections (coronal plane) illustrate bilateral CTEPH vascular lesions at pulmonary arterial phase (arrows point to stenosis and poststenosis dilatation, webs and endoluminal defect (e)) and dilated right-sided bronchial arteries at later phase of data acquisition larrows (f)).

high contrast agent volume and the concern for renal toxicity, as well as the requirement for forceful injection that may increase perfusion pressure in the peripheral pulmonary vasculature and cause pulmonary injury [97].

Poor subpleural perfusion in the capillary phase of pulmonary angiography, suggesting the presence of small vessel disease with diffuse distal thrombosis, is a predictor of BPA failure [94]. TANiguchiet al. [94] showed that in patients with inoperable CTEPH, bronchial artery total area in the normally perfused group was larger than that of the poorly perfused group. Poorly developed bronchial arteries might be involved in the development of diffuse distal thrombosis in patients with CTEPH [83].

\section{Question 5: Should imaging be performed after treatment of $\mathrm{PH}$ ?}

\section{CTEPH after PEA or BPA}

The main goals of all treatment modalities for CTEPH, especially PEA and BPA, are to improve symptoms (ideally to a stage where the patient has recovered from CTEPH-related physical limitations) and to improve pulmonary haemodynamics with the ambition to normalise or near-normalise pulmonary haemodynamics at rest. Hence, the initial focus of the postprocedural assessment in patients who underwent PEA or BPA is their exercise capacity (e.g. 6-min walk test), haemodynamics at rest, and RV function. After PEA surgery, a reduction of the PA pressure to less than or equal to $25 \mathrm{mmHg}$ at rest is 

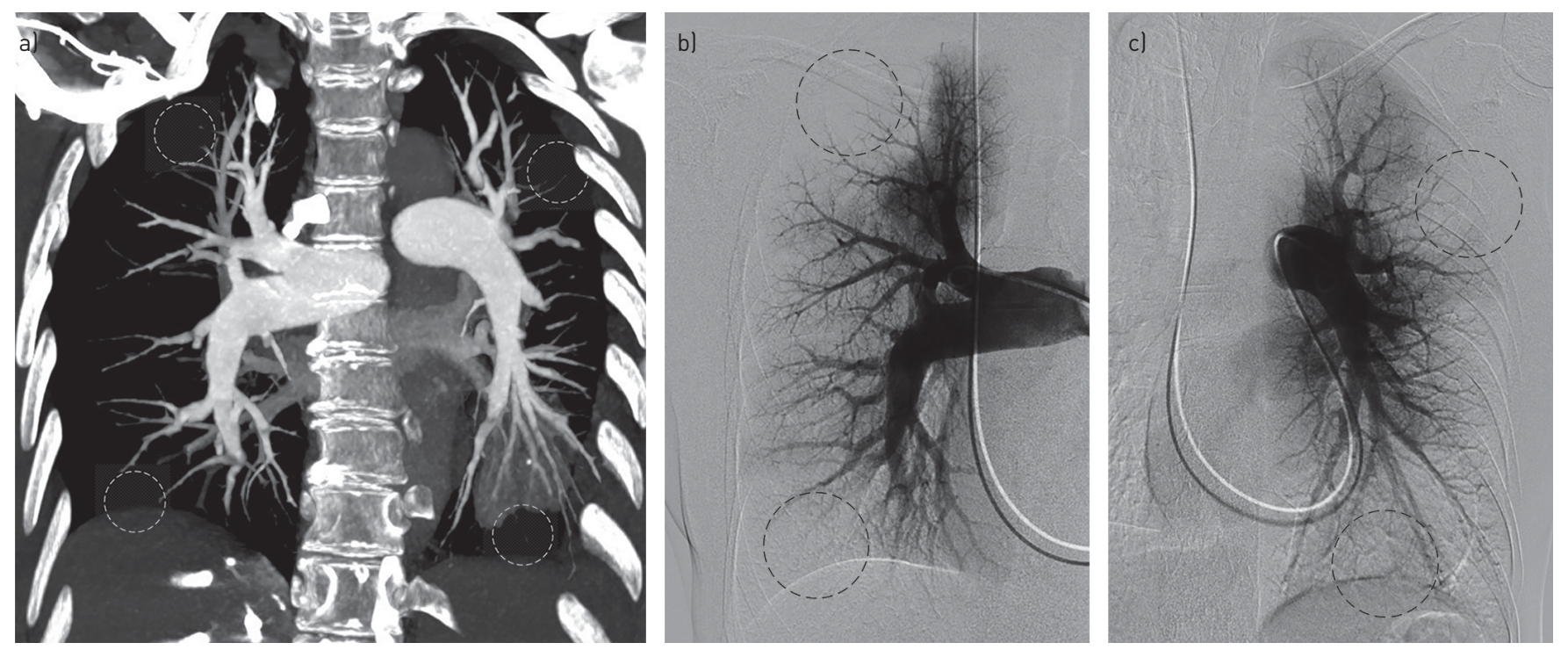

FIGURE $10 \mathrm{a}-\mathrm{c}$ ) Images show CT angiography and pulmonary angiographic evaluation in a 28-year-old patient with peripheral chronic thromboembolic pulmonary hypertension. Maximum intensity projection (coronal plane) (a) and corresponding right (b) and left (c) anteroposterior views of digital pulmonary angiographic study. Presence of vessel pruning and poor distal perfusion (dotted circles) on peripheral pulmonary arteries on CT angiographic reformat and corresponding perfusion defects (dotted circles) on angiographic views.

achieved in about $50 \%$ of patients; another $30 \%$ achieve nearly normalised pulmonary haemodynamics with mean PA pressures between $25 \mathrm{mmHg}$ and $30 \mathrm{mmHg}$ [98]. For BPA, large-scale long-term data are not yet available, but the proportion of patients attaining normal or near-normal pulmonary haemodynamics at rest is lower than with PEA surgery [95, 99-101]. However, BPA results improve after

FIGURE 11 Image shows digital subtraction pulmonary angiography (right-sided injection) performed in a 55-year-old woman with inoperable chronic thromboembolic pulmonary hypertension. On this anteroposterior view obtained at capillary phase of angiographic study, note poor subpleural perfusion (arrows).

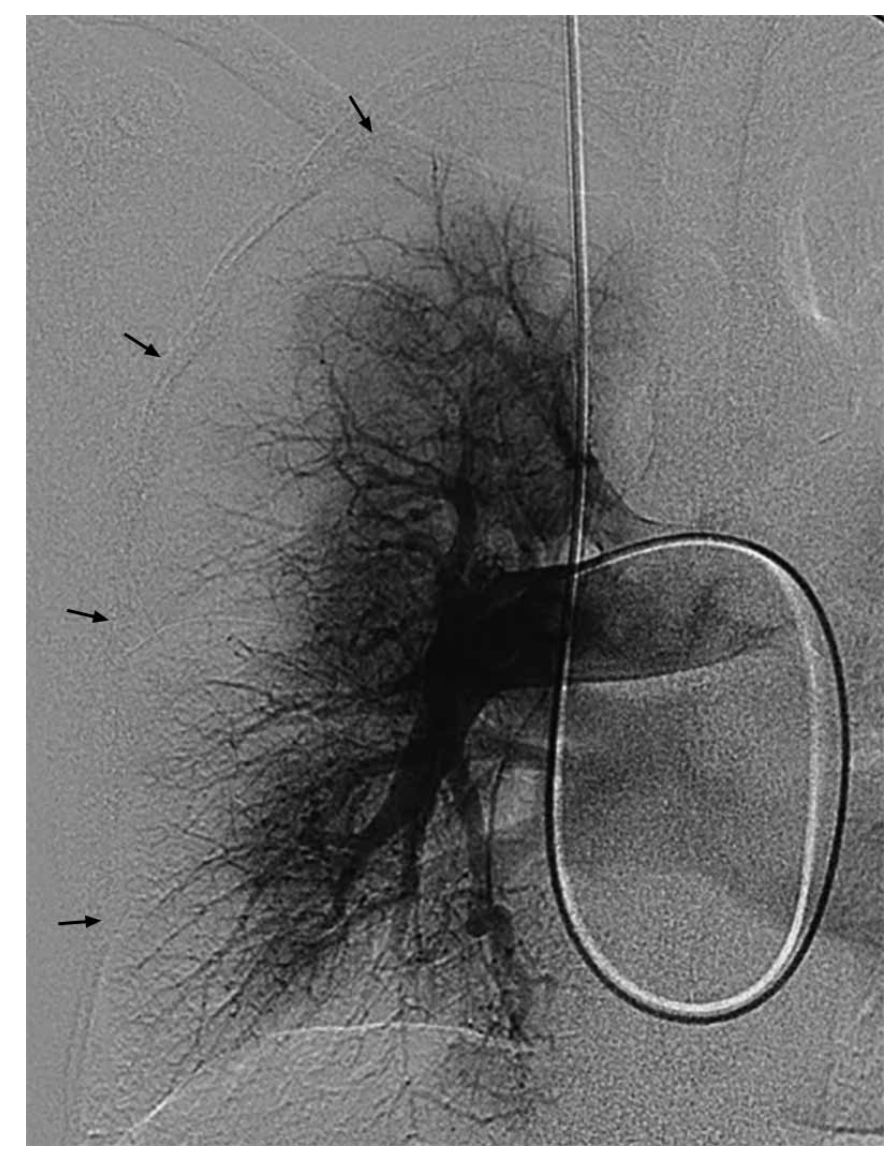


an initial learning curve [96]. Moreover, recent data indicate that the different treatment options are likely to be complementary; combining treatment options leads to marked pulmonary vascular resistance reduction, as recently demonstrated in the Riociguat versus Balloon Pulmonary Angioplasty in Non-operable Chronic Thrombo-embolic Pulmonary Hypertension, or RACE, study showing added benefit of BPA on top of initial riociguat therapy and vice versa [102].

Normalisation or near-normalisation of pulmonary haemodynamics after PEA or BPA is usually accompanied by substantial symptomatic improvement. In patients for whom these treatment goals have been met, there is usually no clinical need for follow-up imaging, except for echocardiography. For patients who remain symptomatic or have residual $\mathrm{PH}$ or both after PEA, imaging is required to determine further treatment options, such as BPA in those patients with residual peripheral CTEPH after PEA [103]. Conventional digital subtraction angiography remains the most widely used imaging tool to triage patients to a repeat PEA or BPA after their first intervention for CTEPH. However, novel imaging tools such as cone-beam CT may provide more detailed information on vessel structure and obstructive lesions [104-106]. Two-dimensional digital subtraction angiography allows quantification of regional lung iodine concentrations before and after BPA [107].

Besides these clinical considerations, there is an abundant literature on the CT and MRI evaluation of pulmonary perfusion, blood flow, and magnitude of residual pulmonary vascular disease after PEA or BPA.

Phase-contrast MRI has been used to demonstrate changes in blood flow in the PA before and after BPA [108]. Perfusion scintigraphy can be used to detect residual perfusion defects after PEA or BPA but is insufficient to guide further treatment. SPECT lung scintigraphy has been described to assess regional lung perfusion changes after BPA [108]. Dual-energy CT may give more detailed information and a higher spatial resolution than does SPECT, providing information on vessel morphology at the same time. In preliminary studies from Japan, assessment of regional lung blood volume before and after BPA with dual-energy CT was found to be more reliable than SPECT imaging [109, 110]. Automated quantification of regional lung blood volume determined with dual-energy CT may also be an option to evaluate changes in regional blood flow and show any new or residual defects in the blood volume (iodine) maps [111]. Dynamic contrast-enhanced MRI perfusion imaging can provide qualitative and semiquantitative assessment of pulmonary perfusion and shows promise for quantitative mapping of pulmonary perfusion in CTEPH [112]. Dynamic contrast-enhanced perfusion methods have been used to demonstrate improvement in regional perfusion parameters, regional blood flow, regional blood volume, and mean pulmonary transit time in patients with CTEPH undergoing BPA [113]. When coupled with gas ventilation MRI, delayed contrast enhancement perfusion MRI has also been used to assess improvement in lung V/Q matching before and after PEA in CTEPH [114].

After successful PEA, cine MRI can demonstrate normalisation of right and left ventricular end-systolic and end-diastolic volumes, re-establishment of interventricular synchrony, a return of the "leftward" ventricular septal bowing, and a decrease in the RV mass [115-117]. Serial MRI studies have shown that reverse cardiac remodelling occurs within the first 4 weeks after PEA with few changes at 3 months and 6 months after surgery [118]. More recently, MASCHKE et al. [119] demonstrated with MRI that global RV function and right and left ventricle synchronisation improved after PEA, but that there were regional differences in the recovery of circumferential and radial function. The clinical implications of these findings remain unknown.

By using serial MRI after BPA, SATO et al. [120] have shown improvement of right and left ventricular ejection fraction. In another study by FUKUI et al. [117], MRI-derived RV function was markedly improved after BPA whereas left ventricular function was largely unchanged. The decline in RV end-systolic and end-diastolic volume was tightly correlated with the decline in pulmonary vascular resistance measured by using right heart catheterisation ( $r=0.74$ and $r=0.72$, respectively; $\mathrm{p}<0.001$ for both), again showing that improved RV function follows afterload reduction. Cardiac MRI has also been used to demonstrate improved ventricular synchrony and an increase in the interventricular septal myocardial T1 values (a return to native myocardial T1 values) after BPA [121, 122].

After BPA, MRI studies combining regional pulmonary parenchymal perfusion measurements and cardiac MRI showed improved pulmonary blood flow in the treated lobes and to a lesser degree in the nontreated lobes, correlating with changes in haemodynamics as well as in the ventricular mass index [113]. Cardiac MRI studies have also been used to predict which patients will recover exercise capacity after PEA in CTEPH. Exercise is limited in those patients with an impaired stroke volume response at MRI [123].

\section{Patients with PAH and CTEPH undergoing medical treatments}

Imaging as part of the follow-up assessment of patients with $\mathrm{PAH}$ or CTEPH receiving medical therapy currently focuses largely on the heart. Transthoracic echocardiography is the most widely used imaging 
tool in clinical practice, but is not the focus of this article. MRI is often considered the reference standard for cardiac imaging because it provides high-resolution three-dimensional imaging and allows reliable quantification of chamber volumes, muscle mass, and blood flows as well as functional assessment of the heart [124]. Neither scintigraphy nor CT has a currently established role in the routine follow-up assessment of patients undergoing medical therapy for PAH or CTEPH. Hence, this section will focus on the use of MRI as follow-up tool in patients with PAH or CTEPH undergoing medical therapy. This section was not supported by a dedicated systematic review of the literature.

Several MRI measurements can be used to determine RV function. Serial cardiac-gated contiguous breath-hold short-axis balanced steady-state free precession cine images are postprocessed to calculate end-diastolic and end-systolic chamber volumes [125]. Of note, the RV stroke volume is the sum of blood ejected into the pulmonary circulation and the amount of tricuspid valve regurgitation. Effective pulmonary blood flow (and thereby, effective stroke volume) can be determined after postprocessing of two-dimensional phase contrast images obtained at the level of the pulmonary valve and/or four-dimensional flow images.

MRI has been used to determine cardiac function in patients undergoing treatment for PAH [126]. At baseline, MRI volumetry-derived RV stroke volume indexed to body surface area, RV ejection fraction, and RV end-diastolic volume index are independent predictors of survival in patients with PAH [74, 75, 127]. The same was found for the RV end-diastolic volume index when corrected for age, sex, and body surface area, and for PA stiffness [80, 128]. During follow-up, a decline in RV stroke volume index as well as increases in RV volumes and decreased left ventricular filling were associated with a high mortality risk [74]. Notably, changes in RV ejection fraction were more predictive of outcome than were changes in pulmonary vascular resistance assessed with right heart catheterisation [75]. Serial MRI has shown that during the initial period of RV failure, there is a parallel decline in longitudinal and circumferential RV strain; over time, the deterioration in longitudinal strain eventually stopped while circumferential strain continued to decline. This was worsened by the progressive left-ward displacement of the interventricular septum [116]. MRI has also been used to demonstrate increased PA stiffness and reduced RV and PA coupling in patients with $\mathrm{PH}$, measurements that may be useful during follow-up assessments as well [129-131]. According to a meta-analysis of articles published in April 2015 [78], the strongest MRI-derived predictors of outcome were RV ejection fraction (pooled hazard ratio, 1.23; 95\% CI: 1.07, 1.41; $\mathrm{p}=0.003$ ), RV end-diastolic volume index (pooled hazard ratio, 1.06; 95\% CI: 1.00, 1.12; $\mathrm{p}=0.049$ ), RV end-systolic volume index (pooled hazard ratio, 1.05; 95\% CI: 1.01, 1.09; $\mathrm{p}=0.013$ ), and left ventricular end-diastolic volume index (pooled hazard ratio, 1.16; 95\% CI: 1.00, 1.34; $\mathrm{p}=0.045)$. RV and left ventricle mass were not associated with outcome [78].

Although some studies have attempted to estimate mean PAP and pulmonary vascular resistance with MRI [132, 133], MRI-derived pressure estimates are still not sufficiently reliable for the follow-up assessment of patients treated for PH. Smaller clinical trials have used MRI-derived end points such as RV mass and RV ejection fraction [134-136] but MRI has not yet been used in large multicentre studies, mainly for logistical reasons and for the simple fact that regulatory agencies have not yet approved drugs based on MRI-derived variables. Patients with PVOD/PCH usually have a poor response to PAH therapy and the use of PAH drugs can be associated with a potential risk of life-threatening pulmonary oedema (figure 2e and f) [137, 138].

\section{Conclusion}

The last decade has shown the importance of noninvasive imaging in the diagnostic approach of pulmonary hypertension $(\mathrm{PH})$, the prognostic classification, and treatment monitoring. Besides this important role acknowledged by current guidelines and practice across centres, imaging modalities continue to evolve, and artificial intelligence has entered the field of medical imaging. Appendix E5 provides an overview of emerging techniques and/or approaches that could push back some current limitations of imaging and open new areas of applications in PH management. Several clinically relevant areas are highlighted. Appendix E6 summarises the key messages of each section of this article. The working group followed the search strategy detailed in appendix E7 (tables E3-E15) and in figure E3.

Author contributions: Guarantors of integrity of entire study, M. Remy-Jardin, Y. Ohno, M. Humbert; study concepts/ study design or data acquisition or data analysis/interpretation, all authors; manuscript drafting or manuscript revision for important intellectual content, all authors; approval of final version of submitted manuscript, all authors; agrees to ensure any questions related to the work are appropriately resolved, all authors; literature research, all authors; clinical studies, L.R. Goodman, G.D. Rubin; statistical analysis, C.J. Ryerson, P.O. Alderson, L.R. Goodman, P. Thistlethwaite; and manuscript editing, all authors.

Support statement: M. Humbert is supported by the Investissement d'Avenir program managed by the French National Research Agency under the grant contract ANR-18-RHUS-0006 (DESTINATION 2024). 
Conflict of interest: M. Remy-Jardin received payment for lectures including service on speakers' bureaus from Siemens Healthineers, Boehringer Ingelheim, Roche, and MSD, outside the submitted work. C.J. Ryerson disclosed no relevant relationships. M.L. Schiebler disclosed no relevant relationships. A.N.C. Leung disclosed no relevant relationships. J.M. Wild disclosed no relevant relationships. M.M. Hoeper is board member and consultant for Acceleron, Actelion, Bayer, Janssen, MSD, and Pfizer, received payment for lectures including service on speakers bureaus from Acceleron, Actelion, Bayer, Janssen, MSD, and Pfizer, outside the submitted work. P.O. Alderson disclosed no relevant relationships. L.R. Goodman disclosed no relevant relationships. J. Mayo received payment for lectures including service on speakers' bureaus from Siemens Healthineers Canada, outside the submitted work. L.B. Haramati disclosed no relevant relationships. Y. Ohno received research grant from Canon Medical Systems, during the conduct of the study; has grants/grants pending with Bayer Pharma, outside the submitted work; received grants-in-aid for scientific research from the Japanese Ministry of Education, Culture, Sports, Science and Technology; received research grant from Smoking Research Foundation; received research grant from Daiichi Sankyo. P. Thistlethwaite disclosed no relevant relationships. E.J.R. van Beek is board member of Aidence, Imbio, and QCTIS, is a consultant for InHealth and Mentholatum, outside the submitted work; is owner and founder of QCTIS; author and spouse are directors. S.L. Knight disclosed no relevant relationships. D.A. Lynch is a consultant for Parexel Imaging, Boehringer Ingelheim, Veracyte, Daiichi Sankyo, and AstraZeneca, received payment for lectures including service on speakers bureaus from Boehringer Ingelheim, outside the submitted work. G.D. Rubin disclosed no relevant relationships. M. Humbert is a board member and consultant for Acceleron, Actelion, Bayer, GSK, and Merck; has grants/grants pending with Acceleron, Actelion, and Bayer; received payment for lectures including service on speakers bureaus from Actelion, Bayer, GSK, and Merck, outside the submitted work.

\section{References}

1 Simonneau G, Montani D, Celermajer DS, et al. Haemodynamic definitions and updated clinical classification of pulmonary hypertension. Eur Respir J 2019; 53: 1801913.

2 Humbert M, Guignabert C, Bonnet S, et al. Pathology and pathobiology of pulmonary hypertension: state of the art and research perspectives. Eur Respir J 2019; 53: 1801887.

3 Galiè N, Channick RN, Frantz RP, et al. Risk stratification and medical therapy of pulmonary arterial hypertension. Eur Respir J 2019; 53: 1801889.

4 Vachiéry JL, Tedford RJ, Rosenkranz S, et al. Pulmonary hypertension due to left heart disease. Eur Respir J 2019; 53: 1801897.

5 Nathan SD, Barbera JA, Gaine SP, et al. Pulmonary hypertension in chronic lung disease and hypoxia. Eur Respir J 2019; 53: 1801914.

6 Kim NH, Delcroix M, Jais X, et al. Chronic thromboembolic pulmonary hypertension. Eur Respir J 2019; 53 1801915.

7 Galiè N, Humbert M, Vachiery JL, et al. 2015 ESC/ERS Guidelines for the diagnosis and treatment of pulmonary hypertension: The Joint Task Force for the Diagnosis and Treatment of Pulmonary Hypertension of the European Society of Cardiology (ESC) and the European Respiratory Society (ERS). Eur Respir J 2015; 46: 903-975.

8 Ascha M, Renapurkar RD, Tonelli AR. A review of imaging modalities in pulmonary hypertension. Ann Thorac Med 2017; 12: 61-73.

9 Frost A, Badesch D, Gibbs JSR, et al. Diagnosis of pulmonary hypertension. Eur Respir J 2019; 53: 1801904

10 Mahammedi A, Oshmyansky A, Hassoun PM, et al. Pulmonary artery measurements in pulmonary hypertension: the role of computed tomography. J Thorac Imaging 2013; 28: 96-103.

11 Lange TJ, Dornia C, Stiefel J, et al. Increased pulmonary artery diameter on chest computed tomography can predict borderline pulmonary hypertension. Pulm Circ 2013; 3: 363-368.

12 Scelsi CL, Bates WB, Melenevsky YV, et al. Egg-and-banana sign: A novel diagnostic CT marker for pulmonary hypertension. AJR Am J Roentgenol 2018; 210: 1235-1239.

13 Shimizu K, Tsujino I, Sato T, et al. Performance of computed tomography-derived pulmonary vasculature metrics in the diagnosis and haemodynamic assessment of pulmonary arterial hypertension. Eur J Radiol 2017; 96: 31-38.

14 McCall RK, Ravenel JG, Nietert PJ, et al. Relationship of main pulmonary artery diameter to pulmonary arterial pressure in scleroderma patients with and without interstitial fibrosis. J Comput Assist Tomogr 2014; 38: 163-168.

15 Boerrigter B, Mauritz GJ, Marcus JT, et al. Progressive dilatation of the main pulmonary artery is a characteristic of pulmonary arterial hypertension and is not related to changes in pressure. Chest 2010; 138: 1395-1401.

16 Chin M, Johns C, Currie BJ, et al. Pulmonary artery size in interstitial lung disease and pulmonary hypertension: association with interstitial lung disease severity and diagnostic utility. Front Cardiovasc Med 2018; 5: 53.

17 Creuzé N, Hoette S, Montani D, et al. Usefulness of cardiovascular magnetic resonance indices to rule in or rule out precapillary pulmonary hypertension. Can J Cardiol 2015; 31: 1469-1476.

18 Swift AJ, Rajaram S, Condliffe R, et al. Diagnostic accuracy of cardiovascular magnetic resonance imaging of right ventricular morphology and function in the assessment of suspected pulmonary hypertension results from the ASPIRE registry. J Cardiovasc Magn Reson 2012; 14: 40.

19 Beiderlinden M, Kuehl H, Boes T, et al. Prevalence of pulmonary hypertension associated with severe acute respiratory distress syndrome: predictive value of computed tomography. Intensive Care Med 2006; 32: 852-857.

20 Dornia C, Lange TJ, Behrens G, et al. Multidetector computed tomography for detection and characterization of pulmonary hypertension in consideration of WHO classification. J Comput Assist Tomogr 2012; 36: 175-180.

21 Spruijt OA, Bogaard HJ, Heijmans MW, et al. Predicting pulmonary hypertension with standard computed tomography pulmonary angiography. Int J Cardiovasc Imaging 2015; 31: 871-879.

22 Terpenning S, Deng M, Hong-Zohlman SN, et al. CT measurement of central pulmonary arteries to diagnose pulmonary hypertension (PHTN): more reliable than valid? Clin Imaging 2016; 40: 821-827.

23 Truong QA, Massaro JM, Rogers IS, et al. Reference values for normal pulmonary artery dimensions by noncontrast cardiac computed tomography: the Framingham Heart Study. Circ Cardiovasc Imaging 2012; 5: $147-154$. 
Lee SH, Kim YJ, Lee HJ, et al. Comparison of CT-determined pulmonary artery diameter, aortic diameter, and their ratio in healthy and diverse clinical conditions. PLoS One 2015; 10: e0126646.

Zisman DA, Karlamangla AS, Ross DJ, et al. High-resolution chest CT findings do not predict the presence of pulmonary hypertension in advanced idiopathic pulmonary fibrosis. Chest 2007; 132: 773-779.

Devaraj A, Wells AU, Meister MG, et al. The effect of diffuse pulmonary fibrosis on the reliability of CT signs of pulmonary hypertension. Radiology 2008; 249: 1042-1049.

Shin S, King CS, Brown AW, et al. Pulmonary artery size as a predictor of pulmonary hypertension and outcomes in patients with chronic obstructive pulmonary disease. Respir Med 2014; 108: 1626-1632.

Iyer AS, Wells JM, Vishin S, et al. CT scan-measured pulmonary artery to aorta ratio and echocardiography for detecting pulmonary hypertension in severe COPD. Chest 2014; 145: 824-832.

Hoesein FA M, Besselink T, Pompe E, et al. Accuracy of CT pulmonary artery diameter for pulmonary hypertension in end-stage COPD. Lung 2016; 194: 813-819.

Alhamad EH, Al-Boukai AA, Al-Kassimi FA, et al. Prediction of pulmonary hypertension in patients with or without interstitial lung disease: reliability of CT findings. Radiology 2011; 260: 875-883.

Truong QA, Bhatia HS, Szymonifka J, et al. A four-tier classification system of pulmonary artery metrics on computed tomography for the diagnosis and prognosis of pulmonary hypertension. J Cardiovasc Comput Tomogr 2018; 12: 60-66.

Rajaram S, Swift AJ, Capener D, et al. Comparison of the diagnostic utility of cardiac magnetic resonance imaging, computed tomography, and echocardiography in assessment of suspected pulmonary arterial hypertension in patients with connective tissue disease. J Rheumatol 2012; 39: 1265-1274.

Moral S, Fernández-Friera L, Stevens G, et al. New index a improves detection of pulmonary hypertension in comparison with other cardiac magnetic resonance indices. Int J Cardiol 2012; 161: 25-30.

Ray JC, Burger C, Mergo P, et al. Pulmonary arterial stiffness assessed by cardiovascular magnetic resonance imaging is a predictor of mild pulmonary arterial hypertension. Int J Cardiovasc Imaging 2019; 35: 1881-1892.

Swift AJ, Rajaram S, Marshall H, et al. Black blood MRI has diagnostic and prognostic value in the assessment of patients with pulmonary hypertension. Eur Radiol 2012; 22: 695-702.

Vogel-Claussen J, Skrok J, Shehata ML, et al. Right and left ventricular myocardial perfusion reserves correlate with right ventricular function and pulmonary hemodynamics in patients with pulmonary arterial hypertension. Radiology 2011; 258: 119-127.

Johns CS, Wild JM, Rajaram S, et al. Identifying at-risk patients with combined pre- and postcapillary pulmonary hypertension using interventricular septal angle at cardiac MRI. Radiology 2018; 289: 61-68.

Revel MP, Faivre JB, Remy-Jardin M, et al. Pulmonary hypertension: ECG-gated 64-section CT angiographic evaluation of new functional parameters as diagnostic criteria. Radiology 2009; 250: 558-566.

Helderman F, Mauritz GJ, Andringa KE, et al. Early onset of retrograde flow in the main pulmonary artery is a characteristic of pulmonary arterial hypertension. J Magn Reson Imaging 2011; 33: 1362-1368.

Sanz J, Kuschnir P, Rius T, et al. Pulmonary arterial hypertension: noninvasive detection with phase-contrast MR imaging. Radiology 2007; 243: 70-79.

Reiter G, Reiter U, Kovacs G, et al. Blood flow vortices along the main pulmonary artery measured with MR imaging for diagnosis of pulmonary hypertension. Radiology 2015; 275: 71-79.

Skrok J, Shehata ML, Mathai S, et al. Pulmonary arterial hypertension: MR imaging-derived first-pass bolus kinetic parameters are biomarkers for pulmonary hemodynamics, cardiac function, and ventricular remodeling. Radiology 2012; 263: 678-687.

Johns CS, Kiely DG, Rajaram S, et al. Diagnosis of pulmonary hypertension with cardiac MRI: derivation and validation of regression models. Radiology 2019; 290: 61-68.

Konstantinides SV, Meyer G, Becattini C, et al. 2019 ESC Guidelines for the diagnosis and management of acute pulmonary embolism developed in collaboration with the European Respiratory Society (ERS): The Task Force for the diagnosis and management of acute pulmonary embolism of the European Society of Cardiology (ESC). Eur Respir J 2019; 54: 1901647.

Bajc M, Neilly JB, Miniati M, et al. EANM guidelines for ventilation/ perfusion scintigraphy: Part 1. Pulmonary imaging with ventilation/perfusion single photon emission tomography. Eur J Nucl Med Mol Imaging 2009; 36: 1356-1370.

Tunariu N, Gibbs SJR, Win Z, et al. Ventilation-perfusion scintigraphy is more sensitive than multidetector CTPA in detecting chronic thromboembolic pulmonary disease as a treatable cause of pulmonary hypertension. J Nucl Med 2007; 48: 680-684.

He J, Fang W, Lv B, et al. Diagnosis of chronic thromboembolic pulmonary hypertension: comparison of ventilation/perfusion scanning and multidetector computed tomography pulmonary angiography with pulmonary angiography. Nucl Med Commun 2012; 33: 459-463.

Stein EG, Haramati LB, Chamarthy M, et al. Success of a safe and simple algorithm to reduce use of CT pulmonary angiography in the emergency department. AJR Am J Roentgenol 2010; 194: 392-397.

Metter D, Tulchinsky M, Freeman LM. Current status of ventilation-perfusion scintigraphy for suspected pulmonary embolism. AJR Am J Roentgenol 2017; 208: 489-494.

Roach PJ, Schembri GP, Bailey DL. V/Q scanning using SPECT and SPECT/ CT. J Nucl Med 2013; 54 $1588-1596$.

Reinartz P, Wildberger JE, Schaefer W, et al. Tomographic imaging in the diagnosis of pulmonary embolism: a comparison between V/Q lung scintigraphy in SPECT technique and multislice spiral CT. J Nucl Med 2004; 45: $1501-1508$.

Grüning T, Drake BE, Farrell SL, et al. Three-year clinical experience with VQ SPECT for diagnosing pulmonary embolism: diagnostic performance. Clin Imaging 2014; 38: 831-835.

Soler X, Hoh CK, Test VJ, et al. Single photon emission computed tomography in chronic thromboembolic pulmonary hypertension. Respirology 2011; 16: 131-137.

Seferian A, Helal B, Jaïs X, et al. Ventilation/perfusion lung scan in pulmonary veno-occlusive disease. Eur Respir J 2012; 40: 75-83.

Montani D, Lau EM, Dorfmüller P, et al. Pulmonary veno-occlusive disease. Eur Respir J 2016; 47: 1518-1534. 
Giordano J, Khung S, Duhamel A, et al. Lung perfusion characteristics in pulmonary arterial hypertension (PAH) and peripheral forms of chronic thromboembolic pulmonary hypertension (pCTEPH): Dual-energy CT experience in 31 patients. Eur Radiol 2017; 27: 1631-1639.

57 Johns CS, Swift AJ, Rajaram S, et al. Lung perfusion: MRI vs. SPECT for screening in suspected chronic thromboembolic pulmonary hypertension. J Magn Reson Imaging 2017; 46: 1693-1697.

58 Resten A, Maitre S, Humbert M, et al. Pulmonary hypertension: CT of the chest in pulmonary venoocclusive disease. AJR Am J Roentgenol 2004; 183: 65-70.

59 Kadowaki T, Yano S, Kobayashi K, et al. Pulmonary capillary hemangiomatosis-like foci detected by high resolution computed tomography. Intern Med 2010; 49: 175-178.

60 Dong C, Zhou M, Liu D, et al. Diagnostic accuracy of computed tomography for chronic thromboembolic pulmonary hypertension: a systematic review and meta-analysis. PLoS One 2015; 10: e0126985.

61 Dournes G, Verdier D, Montaudon M, et al. Dual-energy CT perfusion and angiography in chronic thromboembolic pulmonary hypertension: diagnostic accuracy and concordance with radionuclide scintigraphy. Eur Radiol 2014; 24: 42-51.

62 Masy M, Giordano J, Petyt G, et al. Dual-energy CT (DECT) lung perfusion in pulmonary hypertension: concordance rate with V/Q scintigraphy in diagnosing chronic thromboembolic pulmonary hypertension (CTEPH). Eur Radiol 2018; 28: 5100-5110.

63 Ende-Verhaar YM, Meijboom LJ, Kroft LJM, et al. Usefulness of standard computed tomography pulmonary angiography performed for acute pulmonary embolism for identification of chronic thromboembolic pulmonary hypertension: results of the InShape III study. J Heart Lung Transplant 2019; 38: 731-738.

64 Nakazawa $\mathrm{T}$, Watanabe $\mathrm{Y}$, Hori $\mathrm{Y}$, et al. Lung perfused blood volume images with dual-energy computed tomography for chronic thromboembolic pulmonary hypertension: correlation to scintigraphy with single-photon emission computed tomography. J Comput Assist Tomogr 2011; 35: 590-595.

65 Meinel FG, Graef A, Thierfelder KM, et al. Automated quantification of pulmonary perfused blood volume by dual-energy CTPA in chronic thromboembolic pulmonary hypertension. Rofo 2014; 186: 151-156.

66 Takagi H, Ota H, Sugimura K, et al. Dual-energy CT to estimate clinical severity of chronic thromboembolic pulmonary hypertension: Comparison with invasive right heart catheterization. Eur J Radiol 2016; 85: $1574-1580$.

67 Renapurkar RD, Bolen MA, Shrikanthan S, et al. Comparative assessment of qualitative and quantitative perfusion with dual-energy $\mathrm{CT}$ and planar and SPECT-CT V/Q scanning in patients with chronic thromboembolic pulmonary hypertension. Cardiovasc Diagn Ther 2018; 8: 414-422.

68 Hong YJ, Kim JY, Choe KO, et al. Different perfusion pattern between acute and chronic pulmonary thromboembolism: evaluation with two-phase dual-energy perfusion CT. AJR Am J Roentgenol 2013; 200: 812-817.

69 Koike H, Sueyoshi E, Sakamoto I, et al. Clinical significance of late phase of lung perfusion blood volume (lung perfusion blood volume) quantified by dual-energy computed tomography in patients with pulmonary thromboembolism. I Thorac Imaging 2017; 32: 43-49.

70 Kröger JR, Gerhardt F, Dumitrescu D, et al. Diagnosis of pulmonary hypertension using spectral-detector CT. Int J Cardiol 2019; 285: 80-85.

71 Piazza G, Goldhaber SZ. Chronic thromboembolic pulmonary hypertension. N Engl J Med 2011; 364: 351-360.

72 McCann C, Gopalan D, Sheares K, et al. Imaging in pulmonary hypertension, part 1: clinical perspectives, classification, imaging techniques and imaging algorithm. Postgrad Med J 2012; 88: 271-279.

73 Gan CT, Lankhaar JW, Westerhof N, et al. Noninvasively assessed pulmonary artery stiffness predicts mortality in pulmonary arterial hypertension. Chest 2007; 132: 1906-1912.

74 van Wolferen SA, Marcus JT, Boonstra A, et al. Prognostic value of right ventricular mass, volume, and function in idiopathic pulmonary arterial hypertension. Eur Heart J 2007; 28: 1250-1257.

75 van de Veerdonk MC, Kind T, Marcus JT, et al. Progressive right ventricular dysfunction in patients with pulmonary arterial hypertension responding to therapy. J Am Coll Cardiol 2011; 58: 2511-2519.

76 Freed BH, Patel AR, Lang RM. Redefining the role of cardiovascular imaging in patients with pulmonary arterial hypertension. Curr Cardiol Rep 2012; 14: 366-373.

77 Yamada Y, Okuda S, Kataoka M, et al. Prognostic value of cardiac magnetic resonance imaging for idiopathic pulmonary arterial hypertension before initiating intravenous prostacyclin therapy. Circ J 2012; 76: 1737-1743.

78 Baggen VJ, Leiner T, Post MC, et al. Cardiac magnetic resonance findings predicting mortality in patients with pulmonary arterial hypertension: a systematic review and meta-analysis. Eur Radiol 2016; 26: 3771-3780.

79 de Siqueira ME, Pozo E, Fernandes VR, et al. Characterization and clinical significance of right ventricular mechanics in pulmonary hypertension evaluated with cardiovascular magnetic resonance feature tracking. J Cardiovasc Magn Reson 2016; 18: 39.

80 Swift AJ, Capener D, Johns C, et al. Magnetic resonance imaging in the prognostic evaluation of patients with pulmonary arterial hypertension. Am J Respir Crit Care Med 2017; 196: 228-239.

81 Saunders LC, Johns CS, Stewart NJ, et al. Diagnostic and prognostic significance of cardiovascular magnetic resonance native myocardial T1 mapping in patients with pulmonary hypertension. J Cardiovasc Magn Reson 2018; 20: 78-89.

82 Dorfmüller P, Günther S, Ghigna MR, et al. Microvascular disease in chronic thromboembolic pulmonary hypertension: a role for pulmonary veins and systemic vasculature. Eur Respir J 2014; 44: 1275-1288.

83 Simonneau G, Torbicki A, Dorfmüller P, et al. The pathophysiology of chronic thromboembolic pulmonary hypertension. Eur Respir Rev 2017; 26: 160112.

84 Helmberger M, Pienn M, Urschler M, et al. Quantification of tortuosity and fractal dimension of the lung vessels in pulmonary hypertension patients. PLoS One 2014; 9: e87515.

85 Galiè N, Saia F, Palazzini M, et al. Left main coronary artery compression in patients with pulmonary arterial hypertension and angina. J Am Coll Cardiol 2017; 69: 2808-2817.

86 Fernando DMG, Thilakarathne SMNK, Wickramasinghe CU. Pulmonary artery dissection-A review of 150 cases. Heart Lung 2019; 48: 428-435.

87 Madani M, Mayer E, Fadel E, et al. Pulmonary endarterectomy. Patient selection, technical challenges, and outcomes. Ann Am Thorac Soc 2016; 13: Suppl. 3, S240-S247. 

Shimura N, Kataoka M, Inami T, et al. Additional percutaneous transluminal pulmonary angioplasty for residual or recurrent pulmonary hypertension after pulmonary endarterectomy. Int J Cardiol 2015; 183: 138-142.

Hinrichs JB, Marquardt S, von Falck C, et al. Comparison of C-arm computed tomography and digital Radiol 2016; 39: 53-63.

105 Hinrichs JB, Renne J, Hoeper MM, et al. Balloon pulmonary angioplasty: applicability of C-Arm CT for procedure guidance. Eur Radiol 2016; 26: 4064-4071.

106 Hinrichs JB, von Falck C, Hoeper MM, et al. Pulmonary artery imaging in patients with chronic thromboembolic pulmonary hypertension: comparison of cone-beam CT and 64-row multidetector CT. $J$ Vasc Interv Radiol 2016; 27: 361-8.e2.

107 Maschke SK, Renne J, Werncke T, et al. Chronic thromboembolic pulmonary hypertension: Evaluation of 2D-perfusion angiography in patients who undergo balloon pulmonary angioplasty. Eur Radiol 2017; 27: 4264-4270.

108 Maruoka Y, Nagao M, Baba S, et al. Three-dimensional fractal analysis of 99mTc-MAA SPECT images in chronic thromboembolic pulmonary hypertension for evaluation of response to balloon pulmonary angioplasty: association with pulmonary arterial pressure. Nucl Med Commun 2017; 38: 480-486.

109 Koike H, Sueyoshi E, Sakamoto I, et al. Quantification of lung perfusion blood volume (lung PBV) by dual-energy CT in patients with chronic thromboembolic pulmonary hypertension (CTEPH) before and after balloon pulmonary angioplasty (BPA): Preliminary results. Eur J Radiol 2016; 85: 1607-1612.

110 Koike H, Sueyoshi E, Sakamoto I, et al. Comparative clinical and predictive value of lung perfusion blood volume CT, lung perfusion SPECT and catheter pulmonary angiography images in patients with chronic thromboembolic pulmonary hypertension before and after balloon pulmonary angioplasty. Eur Radiol 2018; 28: 5091-5099.

111 Zhai Z, Ota H, Staring M, et al. Treatment effect of balloon pulmonary angioplasty in chronic thromboembolic pulmonary hypertension quantified by automatic comparative imaging in computed tomography pulmonary angiography. Invest Radiol 2018; 53: 286-292.

112 Bell LC, Wang K, Munoz Del Rio A. Comparison of models and contrast agents for improved signal and signal linearity in dynamic contrast-enhanced pulmonary magnetic resonance imaging. Invest Radiol 2015; 50: 174-178.

113 Schoenfeld C, Hinrichs JB, Olsson KM, et al. Cardio-pulmonary MRI for detection of treatment response after a single BPA treatment session in CTEPH patients. Eur Radiol 2019; 29: 1693-1702.

114 Marshall H, Kiely DG, Parra-Robles J, et al. Magnetic resonance imaging of ventilation and perfusion changes in response to pulmonary endarterectomy in chronic thromboembolic pulmonary hypertension. Am J Respir Crit Care Med 2014; 190: e18-e19.

115 Reesink HJ, Marcus JT, Tulevski II, et al. Reverse right ventricular remodeling after pulmonary endarterectomy in patients with chronic thromboembolic pulmonary hypertension: utility of magnetic resonance imaging to demonstrate restoration of the right ventricle. J Thorac Cardiovasc Surg 2007; 133: 58-64.

116 Mauritz GJ, Vonk-Noordegraaf A, Kind T, et al. Pulmonary endarterectomy normalizes interventricular dyssynchrony and right ventricular systolic wall stress. J Cardiovasc Magn Reson 2012; 14: 5.

117 Fukui S, Ogo T, Morita Y, et al. Right ventricular reverse remodelling after balloon pulmonary angioplasty. Eur Respir J 2014; 43: 1394-1402. 

endarterectomy in patients with chronic pulmonary thromboembolism. Eur Radiol 2008; 18: 792-799.

119 Maschke SK, Schoenfeld CO, Kaireit TF, et al. MRI-derived regional bi-ventricular function in patients with chronic thromboembolic pulmonary hypertension before and after pulmonary endarterectomy. Acad Radiol 2018; 25: 1540-1547.

120 Sato H, Ota H, Sugimura K, et al. Balloon pulmonary angioplasty improves biventricular functions and pulmonary flow in chronic thromboembolic pulmonary hypertension. Circ J 2016; 80: 1470-1477.

121 Yamasaki Y, Nagao M, Abe K, et al. Balloon pulmonary angioplasty improves interventricular dyssynchrony in patients with inoperable chronic thromboembolic pulmonary hypertension: a cardiac MR imaging study. Int $J$ Cardiovasc Imaging 2017; 33: 229-239.

122 Roller FC, Kriechbaum S, Breithecker A, et al. Correlation of native T1 mapping with right ventricular function and pulmonary haemodynamics in patients with chronic thromboembolic pulmonary hypertension before and after balloon pulmonary angioplasty. Eur Radiol 2019; 29: 1565-1573.

123 Surie S, van der Plas MN, Marcus JT, et al. Effect of pulmonary endarterectomy for chronic thromboembolic pulmonary hypertension on stroke volume response to exercise. Am J Cardiol 2014; 114: 136-140.

124 Freed BH, Collins JD, François CJ, et al. MR and CT imaging for the evaluation of pulmonary hypertension. JACC Cardiovasc Imaging 2016; 9: 715-732.

125 Grothues F, Moon JC, Bellenger NG, et al. Interstudy reproducibility of right ventricular volumes, function, and mass with cardiovascular magnetic resonance. Am Heart J 2004; 147: 218-223.

126 Peacock AJ, Crawley S, McLure L, et al. Changes in right ventricular function measured by cardiac magnetic resonance imaging in patients receiving pulmonary arterial hypertension-targeted therapy: the EURO-MR study. Circ Cardiovasc Imaging 2014; 7: 107-114.

127 van Wolferen SA, van de Veerdonk MC, Mauritz GJ, et al. Clinically significant change in stroke volume in pulmonary hypertension. Chest 2011; 139: 1003-1009.

128 Swift AJ, Rajaram S, Campbell MJ, et al. Prognostic value of cardiovascular magnetic resonance imaging measurements corrected for age and sex in idiopathic pulmonary arterial hypertension. Circ Cardiovasc Imaging 2014; 7: 100-106.

129 Sanz J, Kariisa M, Dellegrottaglie S, et al. Evaluation of pulmonary artery stiffness in pulmonary hypertension with cardiac magnetic resonance. JACC Cardiovasc Imaging 2009; 2: 286-295.

130 Brewis MJ, Bellofiore A, Vanderpool RR, et al. Imaging right ventricular function to predict outcome in pulmonary arterial hypertension. Int J Cardiol 2016; 218: 206-211.

131 Vanderpool RR, Pinsky MR, Naeije R, et al. RV-pulmonary arterial coupling predicts outcome in patients referred for pulmonary hypertension. Heart 2015; 101: 37-43.

132 Mousseaux E, Tasu JP, Jolivet O, et al. Pulmonary arterial resistance: noninvasive measurement with indexes of pulmonary flow estimated at velocity-encoded MR imaging-preliminary experience. Radiology 1999; 212: 896-902.

133 Swift AJ, Rajaram S, Hurdman J, et al. Noninvasive estimation of PA pressure, flow, and resistance with CMR imaging: derivation and prospective validation study from the ASPIRE registry. JACC Cardiovasc Imaging 2013; 6: $1036-1047$.

134 Wilkins MR, Ali O, Bradlow W, et al. Simvastatin as a treatment for pulmonary hypertension trial. Am J Respir Crit Care Med 2010; 181: 1106-1113.

135 Wilkins MR, Paul GA, Strange JW, et al. Sildenafil versus Endothelin Receptor Antagonist for Pulmonary Hypertension (SERAPH) study. Am J Respir Crit Care Med 2005; 171: 1292-1297.

136 Chin KM, Kingman M, de Lemos JA, et al. Changes in right ventricular structure and function assessed using cardiac magnetic resonance imaging in bosentan-treated patients with pulmonary arterial hypertension. Am $J$ Cardiol 2008; 101: 1669-1672.

137 Montani D, Achouh L, Dorfmüller P, et al. Pulmonary veno-occlusive disease: clinical, functional, radiologic, and hemodynamic characteristics and outcome of 24 cases confirmed by histology. Medicine (Baltimore) 2008; 87: 220-233.

138 Montani D, Girerd B, Jaïs X, et al. Clinical phenotypes and outcomes of heritable and sporadic pulmonary veno-occlusive disease: a population-based study. Lancet Respir Med 2017; 5: 125-134. 